\title{
1 Genomic and anatomical comparisons of skin support independent 2 adaptation to life in water by cetaceans and hippos
}

5 Mark S. Springer ${ }^{1, \#, *}$, Christian F.Guerrero-Juarez $z^{2,3,4,5, \#, \text { Matthias Huelsmann }}{ }^{6,7,8, \#, \dagger, \downarrow}$, Matthew 6 A. Collin ${ }^{1,9}$, Kerri Danil ${ }^{10}$, Michael R. McGowen ${ }^{11}$, Ji Won Oh ${ }^{12,13,14}$, Raul Ramos ${ }^{3,4,5}$, Michael 7 Hiller ${ }^{6,7,8,15,16,17, *}$, Maksim V. Plikus ${ }^{3,4,5, *}$, John Gatesy ${ }^{18, *}$

${ }^{1}$ Department of Evolution, Ecology, and Organismal Biology, University of California, Riverside, CA 1192521, USA

$12{ }^{2}$ Department of Mathematics, University of California, Irvine, Irvine, CA 92697, USA

$13{ }^{3}$ NSF-Simons Center for Multiscale Cell Fate Research, University of California, Irvine, Irvine, CA 1492697, USA

$15{ }^{4}$ Department of Developmental and Cell Biology, University of California, Irvine, Irvine, CA 92697, 16 USA

$17{ }^{5}$ Sue and Bill Gross Stem Cell Research Center, University of California, Irvine, Irvine, CA 92697, USA

$18{ }^{6}$ Max Planck Institute of Molecular Cell Biology and Genetics, 01307 Dresden,

19 Germany

$20 \quad{ }^{7}$ Max Planck Institute for the Physics of Complex Systems, 01187

21 Dresden, Germany

$22 \quad{ }^{8}$ Center for Systems Biology Dresden, 01307 Dresden, Germany

$23{ }^{9}$ Department of Botany \& Plant Sciences, University of California, Riverside, CA 92521, USA

$24{ }^{10}$ Southwest Fisheries Science Center, National Marine Fisheries Service, National Oceanic and 25 Atmospheric Administration, La Jolla, CA 92037 USA

$26{ }^{11}$ Department of Vertebrate Zoology, Smithsonian Museum of Natural History, 10th \& Constitution Ave.

27 NW, Washington DC 20560, USA

$28{ }^{12}$ Department of Anatomy, School of Medicine, Kyungpook National University, Daegu, Korea

$29{ }^{13}$ Biomedical Research Institute, Kyungpook National University Hospital, Daegu, Korea

$30 \quad{ }^{14}$ Hair Transplantation Center, Kyungpook National University Hospital, Daegu, Korea

$31{ }^{15}$ LOEWE Centre for Translational Biodiversity Genomics, 60325 Frankfurt, Germany

$32{ }^{16}$ Senckenberg Research Institute, 60325 Frankfurt, Germany 
$33{ }^{17}$ Goethe-University, Faculty of Biosciences, 60438 Frankfurt, Germany

$34{ }^{18}$ Division of Vertebrate Zoology and Sackler Institute for Comparative Genomics, American Museum of

35 Natural History, New York, NY 10024, USA

36

37 \# Co-first authors

$38 *$ Corresponding authors: MSS springer@ucr.edu, MH michael.hiller@,senckenberg.de, MVP

39 plikus@uci.edu, JG jgatesy@amnh.org

$40 \dagger$ Present address: Department of Environmental Microbiology, Eawag, 8600 Dübendorf,

41 Switzerland

$42+$ Present address: Department of Environmental Systems Science, ETH Zurich, 8092 Zürich,

\section{Switzerland}

44

45

46

47 


\section{SUMMARY}

The macroevolutionary transition from terra firma to obligatory inhabitance of the marine hydrosphere has occurred twice in the history of Mammalia: Cetacea and Sirenia. In the case of

52 Cetacea (whales, dolphins, porpoises), molecular phylogenies provide unambiguous evidence 53 that fully aquatic cetaceans and semiaquatic hippopotamids (hippos) are each other's closest

54 living relatives. Ancestral reconstructions further suggest that some adaptations to the aquatic 55 realm evolved in the common ancestor of Cetancodonta (Cetacea+Hippopotamidae). An 56 alternative hypothesis is that these adaptations evolved independently in cetaceans and hippos.

57 Here, we focus on the integumentary system and evaluate these hypotheses by integrating new 58 histological data for cetaceans and hippos, the first genome-scale data for pygmy hippopotamus, and comprehensive genomic screens and molecular evolutionary analyses for protein-coding genes that have been inactivated in hippos and cetaceans. We identified ten skin-related genes that are inactivated in both cetaceans and hippos, including genes that are related to sebaceous glands, hair follicles, and epidermal differentiation. However, none of these genes exhibit inactivating mutations that are shared by cetaceans and hippos. Mean dates for the inactivation of skin genes in these two clades serve as proxies for phenotypic changes and suggest that hair reduction/loss, the loss of sebaceous glands, and changes to the keratinization program occurred $\sim 16$ million years earlier in cetaceans $(\sim 46.5 \mathrm{Ma})$ than in hippos $(\sim 30.5 \mathrm{Ma})$. These results, together with histological differences in the integument and prior analyses of oxygen isotopes from stem hippopotamids ("anthracotheres"), support the hypothesis that aquatic adaptations evolved independently in hippos and cetaceans.

Keywords: Cetacea, epidermis, gene loss, Hippopotamidae, histology, skin

\section{INTRODUCTION}

75 The long evolutionary history of Mammalia is mostly one of deployment and adaptation to 76 different terrestrial habitats. Nevertheless, numerous mammalian clades have returned to aquatic 77 habitats, either on a part-time basis or with full commitment to the aquatic realm. Fully aquatic 78 clades include Cetacea and Sirenia, and in both cases there are extinct taxa that document the 
macroevolutionary transition from land to water [1,2]. Semiaquatic clades are much more

80 numerous and examples are found in a wide range of mammalian orders such as Monotremata

81 (platypuses), Didelphimorphia (water opossums), Afrosoricida (otter shrews), Rodentia

82 (muskrats, beavers, capybaras), Eulipotyphla (desmans, star-nosed moles), Carnivora (pinnipeds,

83 otters, mink), and Cetartiodactyla (hippos). Adaptations to aquatic habitats are most extreme in

84 fully aquatic forms where virtually every organ system has been highly modified in conjunction

85 with the transition to life in the water. For example, locomotory adaptations in cetaceans include

86 hind limb loss, modification of the front limbs into flippers, and conversion of the tail into a

87 powerful fluke [1]. At the level of sensory systems, cetaceans have highly modified eyes with

88 reduction or loss of color vision [3], olfactory structures that are highly reduced or absent [4,5],

89 and in the case of odontocetes (toothed whales) ultrasonic hearing that enables echolocation [6].

Cetaceans also show major changes to their integument. By contrast with terrestrial

91 mammals, the skin of fully aquatic mammals constantly interacts with dense, viscous and highly

92 thermally conductive water, which poses unique physical challenges to its outer surface. The

93 epidermis of cetaceans is unusually thick and undergoes constant cellular renewal [7-13]. Even

94 with its increased thickness there are only three distinct histological layers - a basal layer

95 (stratum basale), an intermediate layer (stratum spinosum), and an outer layer (stratum corneum)

96 [14]. The stratum granulosum, which in land mammals lies beneath the stratum corneum, is

97 either ill-defined or absent [10,15]. The exceptionally tall epidermis provides additional

98 mechanical and thermal protection, and its fast rate of sloughing and extensive epidermal-dermal

99 interdigitations guard against potential damage from shear stress during locomotion [16]. The

100 stratum basale forms deep root-like projections, known as rete ridges, that extend into the

101 underlying dermis [17-19]. Extensive cytoplasmic lipid vacuoles are also present in the stratum

102 spinosum and stratum corneum keratinocytes [20-22], and have been speculated to play

103 metabolic and/or thermo-insulating roles [22,23]. Unlike in terrestrial mammals, cells of the

104 stratum corneum retain nuclei and do not become fully keratinized in cetaceans [14]. This is

105 likely due to fully aquatic mammals not needing a functional epidermal barrier to a dry

106 environment [24]. The cetacean dermis is also thickened and consists of an upper papillary layer

107 that intricately interdigitates with the epidermis and a lower reticular layer that gradually

108 transitions into an adipose layer called blubber [10,11,18,25,26]. 
Cetaceans have dramatically reduced the diversity, density, and distribution of

110 ectodermal appendages including hair follicles and skin glands [27]. They show no evidence of 111 pelage (i.e., fur type) hair follicle formation during embryonic development although vibrissa

112 follicles (i.e., whiskers) form on the head [28-32]. Mysticetes and some odontocetes cyclically 113 grow whisker hairs as adults, but most odontocetes lose their whiskers as adults and convert 114 vibrissa follicles into degenerated pits (i.e., crypts) thought to perform sensory functions $115[30,33,34]$. Typical hair follicles in terrestrial mammals are associated with oil-secreting 116 sebaceous glands, but these are lacking in the published histology of cetacean vibrissa follicles $117[31,32,35]$. Cetaceans also lack sweat glands [1,14,27].

118 Among extant semiaquatic forms, hippos are the largest herbivores [36]. Both extant 119 species (Hippopotamus amphibius [river hippo], Choeropsis liberiensis [pygmy hippo]) are 120 nocturnal. Hippos spend their days in the water where they remain cool, but emerge at dusk to 121 feed on grasses and other vegetation. H. amphibius and C. liberiensis have superficially similar122 looking skin, with histological studies primarily on the former [15,37,38] with one recent 123 exception [39]. Similar to cetaceans, adult H. amphibius has a thick epidermis and its stratum 124 basale forms distinct projections into the papillary dermis [15]. H. amphibius also shows 125 elevated levels of lipid storage in the epidermis. However, as compared to cetaceans, most 126 prominent lipid deposits occur in intercellular locations within the stratum corneum [23]. Hippos 127 have numerous bristle-like whiskers on their muzzle and tail, but unlike cetaceans they also have 128 pelage hairs that are sparsely distributed across most of the body [15]. Sebaceous glands have not 129 been reported in hippos, but previous histological studies have only examined limited regions of 130 the body [15,39]. Hippo skin contains anatomically complex sweat glands [37,38] that secrete a 131 distinct red-orange pigmented sweat that is thought to have sunscreen and/or antimicrobial 132 properties $[40,41]$.

133 The traditional view based on phylogenetic interpretations of morphology is that 134 cetaceans are excluded from a monophyletic Artiodactyla (even-toed hoofed mammals) $[42,43]$ 135 and that hippopotamids are the sister taxon to pigs (Suidae) and/or peccaries (Tayassuidae) [44136 48]. However, molecular studies challenged this view and eventually provided conclusive 137 evidence that cetaceans are nested within Artiodactyla [49,50], specifically as the sister taxon to 138 Hippopotamidae [51-54]. 
Given that cetaceans and hippopotamids share a variety of morphological and behavioral

140 characters that may be related to aquatic habitats (hairless or nearly hairless body, lack of

141 sebaceous glands, lack of scrotal testes, underwater parturition and nursing of young, underwater

142 detection of sound directionality), the most parsimonious hypothesis is that these shared

143 characters evolved in the common ancestor of these two clades (= Cetancodonta) and that this

144 common ancestor was semiaquatic [51,52,55,56] (Figure 1A). O'Leary and Gatesy [57] argued

145 in favor of this common origin hypothesis based on ancestral reconstructions of underwater

146 hearing and other aquatic characters. Gatesy et al. [1] favored the aquatic ancestry hypothesis,

147 specifically in freshwater, based on oxygen isotope values in pakicetid cetaceans, the presence of

148 dense, osteosclerotic bones in both hippos and basal stem cetaceans (raoellids, pakicetids), as

149 well as shared behavioral and soft-anatomical traits. Alternatively, semiaquatic adaptations may

150 have evolved convergently in hippos and cetaceans [36] (Figure 1B). In part, support for these

151 two competing hypotheses turns on the phylogenetic placement of various 'Anthracotheriidae',

152 which collectively are the paraphyletic stem group to Hippopotamidae. Some anthracotheres in

153 the subfamilies Anthrocotheriinae (e.g., Anthracotherium) and Microbunodontinae (e.g.,

154 Microbunodon) are inferred to have been terrestrial based on oxygen isotope values, but

155 members of Bothriodontinae (e.g., Bothriogenys, Merycopotamus, Libycosaurus) have values

156 that are consistent with a semiaquatic lifestyle [58-62]. Cooper et al. [62] performed ancestral

157 reconstructions on the microanatomy of the transitional zone between the medullary cavity and

158 the cortical compacta of the tibia for a data set that included both anthracotheres and stem

159 cetaceans ("archaeocetes") and concluded that the most recent common ancestor of Cetancodonta

160 was probably semiaquatic. More recently, Soe et al. [63] reported new skeletal material for the

161 Eocene anthracotheriid Siamotherium, which they recovered as the most basal genus of

162 anthracotheres in their phylogenetic analysis. Soe et al. [63] concluded that there is no evidence

163 of clear-cut aquatic adaptations in Siamotherium fossils. These authors did not perform ancestral-

164 state reconstructions, but the successive placement of two presumably terrestrial anthracothere

165 clades (Siamotherium, Anthracotheriinae) at the base of Hippopotamoidea suggests that aquatic

166 specializations in hippopotamids and cetaceans are convergent.

167 At the molecular level, positive selection analyses on genomic/transcriptomic data

168 provide minimal support for shared aquatic adaptations in the ancestry of Cetancodonta [64].

169 However, given that most aquatic similarities between cetaceans and hippos are in the skin and 
170 that branch-site selection analyses can have weak statistical power, a more promising approach

171 may be to search for skin genes that have been inactivated in the common ancestor of cetaceans

172 and hippos that relate to aquatic specialization of the skin. Previous authors have successfully

173 employed this approach to identify numerous skin genes that were inactivated in the common

174 ancestor of cetaceans, either with a candidate-gene approach [16,24,65] or with comprehensive 175 genomic screens [66-68]. To date, only two candidate gene studies [69-70] have searched for

176 candidate skin genes that are inactivated in cetaceans and hippos. Springer and Gatesy [69]

177 reported that two skin-related genes, MC5R and PSORS1C2, are inactivated in cetaceans but not

178 hippos. Lopes-Marques et al. [70], in turn, reported independent inactivation of two different 179 sebaceous gland genes (AWAT1, MOGAT3) in hippos and cetaceans. Hence, it remains to be 180 determined if a comprehensive screen [sensu 67] will reveal additional skin genes that have been 181 inactivated in both cetaceans and hippos.

182 Here, we present new morphological and molecular evidence to evaluate competing 183 hypotheses that aquatic adaptations evolved in the common ancestor of cetaceans and hippos 184 versus independently in these two groups (Figure 1). First, we provide histological data for 185 different regions of the integument in two cetacean species (Tursiops truncatus [bottlenose 186 dolphin], Eschrichtius robustus [gray whale]) and both extant hippos (Hippopotamus amphibius 187 [river hippo], Choeropsis liberiensis [pygmy hippo]). Next, we perform a comprehensive screen 188 of genomes from representative cetaceans and hippopotamids (including new Illumina data for 189 the pygmy hippopotamus) for protein-coding genes that have been inactivated in both of these 190 clades. We then assess the timing of pseudogenization for these genes based on the 191 presence/absence of shared inactivating mutations and selection intensity $(\mathrm{dN} / \mathrm{dS})$ analyses that 192 are integrated with a molecular timetree. Finally, we synthesize our molecular and histological 193 findings with previous studies and discuss these results in the context of the rich fossil record for 194 stem cetaceans (“archaeocetes”) and stem hippos (“anthracotheres”).

\section{RESULTS AND DISCUSSION}

\section{Comparative Skin Histology Between Terrestrial and Aquatic Cetartiodactyla}

199 We analyzed skin samples from numerous body regions (face, eyelid, ear, dorsum, ventrum and 200 tail) in both hippopotamid species, and from the snout region of one odontocete (bottlenose 
201 dolphin) and one mysticete (gray whale). Table 1 summarizes features of the skin in these taxa

202 and also includes data from the literature for terrestrial mammals including humans and two 203 cetartiodactyls (cow, pig) that are close relatives of Cetancodonta [71-79].

Hippos and cetaceans have prominent differences in the thickness and organization of the epidermis (Figure 2). Consistent with previous reports [17-19], the facial epidermis in adult Eschrichtius robustus (Figure 2E) and neonatal Tursiops truncatus (Figure 2F-G) is very thick, with a wide stratum spinosum, and an undulated stratum basale with deep root-like rete ridges that extend into the dermis. By contrast, the epidermis in neonatal pygmy hippo is thin, with only shallow rete ridges (Figure 2A-D). Among different anatomical sites, epidermal rete ridges are most prominent in the lip and tail and least prominent in the ear and ventral skin.

Hippo skin contains hair follicles of both pelage and vibrissa morphology. Prominent

212 vibrissa follicles that contain collagen capsules and ringwulst (ring-like dermal structure that 213 surrounds the follicle) were observed in the upper lip skin (Figure 2A; Supplemental Figure

214 S1C). Some tail-tip hair follicles also display collagen capsules (Figure 2B; Supplemental Figure 215 S1E), suggesting that the tail region might contain a mixture of pelage and vibrissa hair types. 216 Hair follicles in ear and eyelid skin have typical pelage morphology, and meibomian glands are 217 absent in the latter (Figure 2D; Supplemental Figure S1A-B, S2C). In all samples studied, hippo 218 hair follicles lack hair-associated sebaceous glands (Figure 2; Supplemental Figure S1). No hair 219 follicles were identified in the available dorsal and ventral skin samples. The facial skin of adult 220 gray whale and neonatal bottlenose dolphin had prominent vibrissa hair follicles (Figure 2E-G), 221 yet their structure differs from that of facial hippo vibrissae. Cetacean vibrissae lack both 222 collagen capsules and ringwulst. In the baleen whale (Figure 2E), but not the dolphin (Figure 2F$223 \mathrm{G})$, the epithelial outer root sheath is highly undulated and peri-follicular nerves are very distinct. 224 In both species, mesenchymal dermal papillae and the epithelial hair matrix, two defining 225 structures of actively growing hair follicles, are present. However, the hair matrix in dolphin 226 vibrissae is uncharacteristically thin. There is no evidence of vibrissa-associated sebaceous 227 glands in either cetacean species that was examined.

Prominent sweat glands are present in pygmy hippo skin in several locations, including 229 the upper lip and both dorsal and ventral skin (Figure 2C-D; Supplemental Figure S2). The 230 structure of the dermis is different in cetaceans and hippos. There are abundant clusters of 231 adipocytes throughout the dermis in Tursiops truncatus (Figure 2G), but we found no 
232 histological evidence for mature adipocytes in hippo skin at all locations studied. In hippos, there

233 are prominent differences in dermal thickness across body sites, with tail and ear dermis being

234 the thinnest.

235 In conclusion, hippo skin is characterized by an epidermis that is thinner than in 236 cetaceans, shallow rete ridges, a dermis of variable thickness without adipocytes, highly 237 specialized sweat glands, and both pelage and vibrissa hair follicles. Sweat glands and both types 238 of hair follicles display differing regional distributions. In contrast, cetacean skin has a distinctly 239 thick and highly undulated epidermis, a thick and adipocyte-rich dermis, and few 240 morphologically-specialized facial vibrissa hair follicles as the only skin appendage. Unlike

241 humans and terrestrial cetartiodactyls, hair-associated sebaceous glands are lacking in hippos and 242 cetaceans (Table 1).

\section{Genomic Screens and Patterns of Gene Inactivation in Cetaceans and Hippos}

245 Next, we investigated the hypothesis of shared versus independent aquatic ancestry using 246 existing and newly-generated genomic data. We first screened genomic alignments with 63 247 mammalian taxa for protein-coding genes that are inactivated in Hippopotamidae and Cetacea 248 but not in terrestrial cetartiodactyls. Our initial screen included Hippopotamus amphibius, one 249 baleen whale (Balaenoptera acutorostrata [common minke whale]), and three toothed whales 250 (Physeter macrocephalus [sperm whale], Orcinus orca [killer whale], Tursiops truncatus 251 [bottlenose dolphin]). Based on these screens, we identified 38 genes that have inactivating 252 mutations (frameshift insertions/deletions, premature stop codons, splice site mutations, deleted 253 exons) or are completely deleted in these taxa (Supplemental Table S1) including ten genes that 254 have primary or sole functions related to skin and its ectodermal appendages (ALOX15, AWAT1, 255 KPRP, KRT2, KRT26, KRT77, KRTAP6-2, KRTAP6-3, KRTAP7-1, TCHHL1). Two genes 256 (KRTAP6-2, KRTAP6-3) were removed from this list because of ambiguous orthology 257 relationships, leaving eight genes for a detailed analysis. We added $A B C C 11$ to this list, which is 258 a candidate gene of interest that is expressed in axillary sweat glands in humans [80,81].

259 Since base errors in genome assemblies can mimic gene-inactivating mutations [82], we 260 first used additional genomic data to confirm the validity of inactivating mutations and thus the 261 loss of function of the nine genes. To this end, we used BLAST to investigate whether 262 inactivating mutations are shared with independently-sequenced and assembled sister species 
genomes, which would indicate that these mutations are real and occurred in the common ancestor of taxa sharing the mutation(s). Our investigation of ten additional cetacean genomes revealed that all nine genes have mutations shared between at least two species, as exemplified in Figure 3A-B. Three of these nine genes (AWAT1, KRTAP7-1, ABCC11) exhibit inactivating mutations shared between odontocetes and mysticetes, indicating gene loss in the stem cetacean lineage (Figure 3C). Two genes (KRT26, KRT77) exhibit large or entire gene deletions in odontocetes and mysticetes, and gene loss dating (below) indicates that both losses happened in the stem cetacean lineage. The distribution of inactivating mutations in ALOX15 suggests that it was independently inactivated on the stem branch of Delphinida, on the stem branch of Physeteridae (sperm whales; two stop codons are shared between Physeter macrocephalus and Kogia breviceps), and in the common ancestor of Balaenoptera acutorostrata and B. bonaerensis

274 (minke whales). Finally, three genes are absent from all cetacean (KPRP and TCHHL1) or all odontocete (KRT2) genomes,. However, large deletions and rearrangements in these loci obscure reconstructions of when these genes were lost because there are no obvious breakpoints that are shared by odontocetes and mysticetes.

Genomic data for Choeropsis liberiensis are required to investigate whether mutations are shared between both extant hippopotamid species. Therefore, we generated $\sim 40 \mathrm{X}$ of Illumina

280 whole genome shotgun data of $C$. liberiensis and mapped these reads to the Hippopotamus amphibius assembly to obtain orthologous sequences. We found that both hippopotamids exhibit 282 shared inactivating mutations in eight of these nine genes (ALOX15, AWAT1, KPRP, KRT2, 283 KRT26, KRT77, KRTAP7-1, TCHHL1) (Figure 3). ABCC11 is intact in H. amphibius, but we 284 detected a two-bp frameshift deletion in exon 14 of C. liberiensis, suggesting a recent loss in 285 pygmy hippo (Figure 3B).

Next we analyzed whether these nine skin-related gene losses have inactivating mutations that are shared by hippos and cetaceans, which would indicate gene inactivation in the common ancestral lineage of extant cetancodontans. We did not find any evidence of inactivating 289 mutations that are shared by hippos and cetaceans. Instead, all nine genes have different 290 mutations in cetaceans and hippopotamids (Figure 3, Supplemental Table S2), indicating that 291 these genes were independently lost in both lineages. In a previous study on candidate sebaceous

292 gland genes, Lopes-Marques et al. [70] reported the convergent loss of both AWAT1 and 293 MOGAT3 in Cetacea and Hippopotamus amphibius. Our results confirm the independent 
inactivation of $A W A T 1$ in these two clades and further suggest that $A W A T 1$ was inactivated in the common ancestor of $H$. amphibius and Choeropsis liberiensis. However, our investigation of MOGAT3 revealed that this gene underwent a tandem duplication, most likely in the common ancestor of the two extant hippopotamids (Figure 4). The pseudogenized copy of MOGAT3 reported by Lopes-Marques et al. [70] is $\sim 15.7 \mathrm{~kb}$ upstream of the functional copy of this gene on NCBI contig PVJP02910399. C. liberiensis retains an intact copy of MOGAT3, but we were unable to find evidence for retention of the pseudogenic paralog in this species. Lopes-Marques et al.'s [70] analyses of a de novo skin transcriptome provide additional support for two copies of MOGAT3 in H. amphibius. One represents transcription from the intact MOGAT3 locus whereas the other represents transcription of the inactivated copy of MOGAT3.

\section{Comparison of Inactivated Skin Genes and Epidermal Phenotypes in Cetaceans and} Hippos

The cetacean epidermis is very thick and renews rapidly, yet does not fully differentiate into the highly keratinized stratum corneum of terrestrial mammals that confers barrier functions. At the genetic level, these modifications are associated with loss of function of numerous genes that are part of the Epidermal Differentiation Complex (EDC), including S100 fused-type protein (CRNN, FLG [in mysticetes and sperm whales], FLG2, HRNR, RPTN, TCHH, TCHHL1, TCHHL2) [27,65] and suprabasal epidermal keratin genes (KRT1, KRT2, KRT9, KRT10, KRT77, KRT23 [odontocetes only], KRT24) [16]. Our analyses on cetacean genomes confirm these findings (Figure 5).

While hippos and cetaceans share reduced differentiation of the epidermis and possess an ill-defined stratum granulosum $[10,15]$, the hippo epidermis also differs in a number of aspects

317 from the cetacean epidermis. In particular, hippo epidermis is much thinner, has shallower rete 318 ridges, and it partially preserves epidermal barrier function as hippos spend substantial time on 319 land. These differences may explain why in comparison with cetaceans, only one EDC gene, 320 TCHHL1 (trichohyalin-like 1), is convergently inactivated in hippos (Figure 5). TCHHL1 is a 321 recently described epidermal gene that is predominantly expressed in the stratum basale and 322 whose specific function in keratinocyte differentiation remains unclear [83,84]. Among 323 suprabasal keratins, only KRT2 and KRT77 are independently inactivated in hippos (Figure 5), 324 and the overall degree of suprabasal keratin inactivation in hippos is less than in obligately- 
aquatic manatees, which are more similar to cetaceans [16]. We also show that other important epidermal genes that were reported as inactivated in cetaceans are intact in hippos. These include terminal keratinocyte differentiation-associated caspase CASP14 [65], PSORS1C2 (psoriasis susceptibility 1 candidate 2) [85], desmosome proteins DSG4 and DSC1, transglutaminase TGM5, and the atypical lipoxygenase $A L O X E 3$ [86]. In summary, cetaceans and hippos both have inactivated copies of EDC and suprabasal keratin genes, but many more genes are knocked out in cetaceans.

Our genome-wide screen identified two new epidermal genes, KPRP and $A L O X 15$, that are independently inactivated in cetaceans and hippos (Figure 5). KPRP (keratinocyte prolinerich protein) is considered to be an epidermal terminal differentiation-associated protein, part of the EDC, that is normally expressed in the stratum granulosum $[87,88]$ - an epidermal layer that is poorly defined in hippos [15] and absent in cetaceans [10]. A recent study has identified significant association between single-nucleotide polymorphism in human KPRP and atopic dermatitis, a skin condition diagnosed by the disrupted epidermal barrier function [89]. Studies in $\mathrm{Kprp}^{+/-}$mutant mice further showed that KPRP haploinsufficiency leads to defective epidermal desmosome structure, a higher than normal detachment rate of differentiated keratinocytes from the stratum corneum, increased transepidermal water loss, and higher susceptibility to skin inflammation in experimental assays [89]. ALOX15 (arachidonate 15-

343 lipoxygenase) is a member of the lipoxygenase family of enzymes that catalyze synthesis of 344 bioactive lipids, including resolvins [90,91]. As the name suggests, resolvins regulate resolution 345 of excessive inflammatory responses and can act on diverse cell types. ALOX15 is highly expressed in mouse epidermis and Axol15 $5^{-/-}$mutant mouse studies suggest that it is important for proper epidermal barrier function. Mutant mice develop a thickened epidermis, expanded expression of stratum basale markers, and increased transepidermal water loss [92]. Both genes are again independently lost in cetaceans and hippos.

We next focused our analysis on genes normally associated with skin appendages, hair follicles, sebaceous glands, and sweat glands. We confirm previous findings that some or all cetaceans have inactivated keratins of the hair inner root sheath: KRT25, KRT26, KRT27, KRT28,

354 KRT33B, KRT34, KRT35, KRT38, KRT39, KRT40, KRT82, KRT83 and KRT84, as well as 355 keratins $K R T 3$ and $K R T 6 B[16,93]$. Of these, hippos have independently inactivated only KRT26. 
Preservations of most hair and nail keratins in hippos is consistent with the fact that unlike cetaceans, hippos have prominent keratinized hoofs [94] and distinct pelage and vibrissa hairs, albeit only in restricted anatomical sites. Particularly, brush-like hairs on hippo tail aid in spreading feces upon defecation, a behavior used by both river hippo and pygmy hippo for territorial marking [95]. Our analyses validate that cetaceans have inactivations in numerous genes associated with sebaceous gland function [69, 70]. Cetaceans are characterized by inactivations in AWAT1, DGAT2L6, FABP9, ELOVL3, MOGAT3 and MC5R. We also show that AWAT1 is inactivated in both hippos; yet unlike Lopes-Marques et al. [70], we show that these species retain an intact copy of MOGAT3 (Figure 4). Finally, we found that the ATP-binding cassette transporter $A B C C 11$, which is associated with axillary sweat gland function in humans, is inactivated in all cetaceans and independently in pygmy, but not river hippo. Both river and pygmy hippos have active sweat glands that produce pigmented secretion; therefore, we speculate that $\mathrm{ABCC} 11$ function is not critical for this unique aspect of hippos' sweat gland biology.

\section{The Timing of Gene Inactivations in Hippopotamidae and Cetacea}

372 To understand when gene losses occurred, we performed $\mathrm{dN} / \mathrm{dS}$ analyses with the coding 373 remnants of these genes and equations from Meredith et al. [96]. We focused on genes that were 374 independently inactivated in Cetacea and Hippopotamidae plus two other selected genes 375 (MOGAT3 and $A B C C 11)$. To obtain robust inactivation dates, we calculated dates using eight different combinations of codon frequency model (CF1, CF2), fixed versus estimated $\omega$ values

377 for the pseudogenic branch category, and one versus two rates for synonymous substitutions 378 (Supplemental Table S3). Mean inactivation dates based on these estimates are shown in Figure 3 and Table 2. Mean estimates for eight genes (ALOX15, AWAT1, KPRP, KRT2, KRT26, KRT77, KRTAP7-1, TCHHL1) that were inactivated on the stem Hippopotamidae branch range from 53.92 to $5.42 \mathrm{Ma}$. These inactivation dates suggest that derived changes in hippopotamid skin, 382 including the loss of sebaceous glands, have a long history that encompasses the entirety of the 383 stem hippopotamid branch. The mean date for inactivation of these eight genes is $\sim 30.5 \mathrm{Ma}$, 384 which is near the midpoint of the stem hippopotamid branch. In addition, $A B C C 11$ is intact in 385 Hippopotamus amphibius but appears to have been inactivated very recently in Choeropsis 386 liberiensis (Figure 3; Table 2). 
In the case of Cetacea, estimated inactivation dates for four genes (ABCC11, AWAT1, KRTAP7-1, MOGAT3) with clear evidence of pseudogenization on the stem cetacean branch based on shared inactivating mutations range from 48.23 to $40.54 \mathrm{Ma}$ (mean $=44.02 \mathrm{Ma})$. Three additional genes are inactivated in all cetaceans, but are completely absent from either odontocetes (KRT2, KRT77) or mysticetes (KRT26). As complete gene deletion could have erased smaller mutations that inactivated these genes earlier in evolution, we used the remnants of these genes to estimate whether loss may have occurred on the stem Cetacea branch. Inactivation dates suggest that two of these genes were pseudogenized on the cetacean stem branch (53.92 $\mathrm{Ma}$ [KRT77], $48.93 \mathrm{Ma}$ [KRT26]) whereas the date for KRT2 [33.64 Ma] is slightly younger than the most recent common ancestor of Cetacea at $\sim 36.72 \mathrm{Ma}$. The mean date for the six genes (ABCC11, AWAT1, KRT26, KRT77, KRTAP7-1, MOGAT3) inactivated on the stem cetacean branch is $\sim 46.5 \mathrm{Ma}$, which is near the midpoint of the stem cetacean branch. Overall, the mean inactivation date for these six genes in cetaceans is $\sim 16.0$ million years older than the mean inactivation date for eight genes that were inactivated on the stem hippo branch. Among four overlapping genes (AWAT1, KRT26, KRT77, KRTAP7-1) with inactivation dates on the stem cetacean and stem hippo branches, the mean date for stem Cetacea (48.00 Ma) is 10.36 Ma older than the mean date for stem hippos (37.46 Ma). Two additional genes (KPRP, TCHHL1) are completely absent in all cetacean genomes that we examined, so the timing of these gene losses on the stem cetacean branch could not be estimated with our methods. Finally, ALOX15 appears to have been independently inactivated in the common ancestor of Delphinida (34.13 Ma), on the terminal branch leading to Physeter $(21.44 \mathrm{Ma})$, and in the common ancestor of Balaenoptera acutorostrata and B. bonaerensis (15.74 Ma) within Mysticeti (ALOX15 is intact in Eschrichtius robustus and Balaena mysticetus).

\section{Integration of Molecular, Histological, and Paleontological Data}

412 Our integrative analysis sheds new light on the key question pertaining to the evolution of

413 Cetancodonta: Did shared morphological and behavioral features associated with aquatic and 414 semiaquatic lifestyles evolve in the common ancestor of this clade or did they evolve 415 independently in Cetacea and Hippopotamidae (Figure 1)? If aquatic features of hippos represent 416 an intermediate condition in the transition from land to sea in the ancestry of Cetacea [1], 417 behavioral study of extant hippos might provide direct insights into the behavior of the earliest 
418 cetaceans form the Eocene. Shared morphological features include the general reduction in 419 density or complete loss of pelage hairs that cover the body, and the loss of sebaceous glands. 420 Previous histological studies that reported the absence of sebaceous glands were inconclusive as 421 they were limited to skin from the trunk, neck, and limbs of Hippopotamus amphibius that have 422 few to no hairs [15]. Sebaceous glands normally form as part of embryonic hair follicle 423 development. Together, sebaceous glands and hair follicles constitute an anatomically connected 424 pilosebaceous unit. Therefore, definitive determination of the presence or absence of sebaceous 425 glands requires a thorough investigation of hair-bearing skin in different regions of the body. We 426 examined several regions of haired skin and provide more definitive evidence for the absence of 427 sebaceous glands around hair follicles than previous studies [15]. We also extended these 428 findings to a second hippopotamid species, Choeropsis liberiensis. Meibomian glands, which are 429 modified sebaceous glands in the eyelid skin, are also absent in H. amphibius, as has also been 430 reported for $C$. liberiensis [39]. Further, examined vibrissa follicles in newborn Tursiops 431 truncatus and adult Eschrichtius robustus also lack sebaceous glands. These findings make a 432 strong case for the complete body-wide absence of sebaceous glands in hippopotamids and 433 cetaceans. The most parsimonious interpretation for the loss of sebaceous glands in hippos and 434 cetaceans is that these glands were lost in the common ancestor of Cetancodonta. Similarly, the 435 most parsimonious interpretation of body hair follicle reduction (hippos) or loss (cetaceans) is 436 that pelage density started to decrease in the common ancestor of hippos and cetaceans. At the 437 same time, the distribution of lipids is intracellular in the highly modified stratum corneum of 438 cetaceans whereas hippos have intercellular stratum corneum lipids, which suggests parallel 439 evolution of the highly modified epidermis in these taxa.

440 If pelage reduction and the loss of sebaceous glands occurred in the common ancestor of 441 Cetancodonta, then we should expect to find evidence of shared inactivating mutations in one or 442 more skin-specific genes in hippos and cetaceans. By contrast, the independent origins 443 hypothesis predicts that we should see convergent gene inactivations in cetaceans and hippos. 444 Our genomic screens identified several skin-specific genes that are inactivated in hippos and 445 cetaceans. Strikingly, none of these genes have inactivating mutations that are shared by hippos 446 and cetaceans. The absence of shared inactivating mutations at multiple gene loci suggests that 447 pelage reduction and the loss of sebaceous glands occurred independently in Hippopotamidae 448 and Cetacea. 
Mean dates for the inactivation of skin genes in these two clades serve as a proxy for phenotypic changes. These dates suggest that pelage reduction/loss, the loss of sebaceous glands, and changes to the keratinization program occurred $\sim 16.0$ million years earlier in Cetacea (46.5 Ma) than in Hippopotamidae (30.5 Ma) based on all estimates for gene inactivations or $\sim 10.5$ million years earlier in Cetacea (48.0 Ma) than in Hippopotamidae (37.5 Ma) based on an overlapping set of four genes (Figure 3, Table 2). The mean date of $248.0-46.5 \mathrm{Ma}$ for Cetacea is older than the first obligately aquatic cetaceans in the family Basilosauridae (e.g., Basilosaurus at $\sim 41 \mathrm{Ma}$ ) and instead corresponds with the oldest protocetids (e.g., Rodhocetus) from the Lutetian (47.8-41.3 Ma), which may have utilized both land and water as sea lions do today [97]. The mean inactivation date of $237.5-30.5$ Ma for hippopotamid skin genes, in turn, is the range of early bothriodontine anthracotheres (37.2-33.9 Ma) that are inferred to be the oldest semiaquatic members of the family Anthracotheriidae [36]. It is also noteworthy that far more skin-related genes have been inactivated in Cetacea than in Hippopotamidae (Figure 5), which is consistent with the more complete reorganization of the epidermis and its derivatives in cetaceans relative to hippopotamids (Table 1; Figures 2 and 5). Finally, our estimates of individual gene inactivations span tens of millions of years for both stem + crown cetaceans and stem + crown hippos (Figure 3, Table 2), suggesting that macroevolutionary changes to aquatic and semiaquatic habitats in these clades, respectively, have long, stepwise histories. Indeed, AWAT1 inactivation on the stem hippopotamid branch and ABCC11 inactivation on the Choeropsis liberiensis branch have estimated pseudogenization dates that are separated by $\sim 54$ million years.

Paleontological evidence also provides an opportunity to evaluate competing hypotheses that aquatic/semiaquatic features of cetaceans and hippos were acquired independently rather

472 than in the common ancestor of this clade (Figure 1). If the initial shift to a semiaquatic lifestyle 473 occurred in the common ancestor of Cetancodonta, then we might expect to find morphological 474 and/or geochemical evidence for this transition in (1) stem cetancodontans that are close to the 475 crown group, (2) the earliest branching stem cetaceans, and (3) the earliest stem hippopotamids. 476 In the case of stem cetaceans, the most primitive and earliest branching clade is Raoellidae, 477 which includes Indohyus. Thewissen et al. [98] reported that Indohyus has a thickened medial 478 wall in the auditory bulla known as the involucrum. They inferred that the involucrum is associated with underwater hearing and that its presence in Indohyus provides evidence that the 
most primitive stem cetaceans were already semiaquatic. Dense limb bones (for ballast) and oxygen isotopic signatures of its teeth also suggest that Indohyus was semiaquatic [98]. Evidence for aquatic/semiaquatic specializations in stem cetancodontans and stem hippopotamids is less forthcoming. In the case of Cetancodonta, definitive stem members of this clade have been difficult to identify owing to the uncertainty of cladistic analyses. Possible stem cetancodontans have included a variety of anthracotheres (e.g., Anthracotherium, Siamotherium [56]; Elomeryx, Heptacodon, Microbunodon [1]), an entelodontid (Brachyhyops [56], a cebochoerid (Cebochoerus [1,99]), and the enigmatic Andrewsarchus [56]. We are not aware of any compelling evidence for aquatic adaptations in any of these taxa. Also, there is an emerging consensus from alternative phylogenetic hypotheses that anthracotheres comprise the paraphyletic stem group that gave rise to Hippopotamidae [36,63,99]. Many anthracotheres (e.g., Anthracotherium, Siamotherium) appear to have been terrestrial based on oxygen isotope values

492 whereas taxa in the subfamily Bothriodontinae have values that are consistent with a semiaquatic 493 lifestyle [58,59,61,62]. However, the phylogenetic placement of presumed terrestrial 494 anthracotheres as basal, stem Hippopotamidae suggests that specializations for an 495 aquatic/semiaquatic lifestyle evolved independently in hippopotamids and cetaceans [36,63]. 496 Thus, paleontological evidence is largely aligned with inactivating mutations in skin-related genes that favor the independent origins hypothesis.

When sister taxa share the same anatomical, physiological, or behavioral features, as is the case for aquatic features in Hippopotamidae and Cetacea, the simplest hypothesis is that 500 these features evolved in their common ancestor. However, our results suggest otherwise and instead support the independent evolution of features that are related to the skin in hippos and cetaceans. Given that most synapomorphies for Cetancodonta are aquatic traits (e.g., hairless or 503 nearly hairless body, lack of sebaceous glands, lack of scrotal testes, underwater 504 parturition/nursing) [1], morphological and behavioral support is very limited for this group if 505 these traits evolved in parallel. Along the same lines, extant pinnipeds have lost their sweet and 506 umami taste receptors. However, loss of these receptors occurred independently in the ancestors 507 of the reciprocally monophyletic Phocidae (seals) and Otaroidea (Otariidae [sea lions, fur seals] $508+$ Odobenidae [walruses]) rather than in the common ancestor of Pinnipedia [100]. Numerous 509 morphological features related to raptorial feeding and hydrodynamic locomotion also appear to 510 have evolved independently in the three extant families of Pinnipedia [101]. In Cetacea, multiple 
511 cranial and postcranial specializations for an aquatic lifestyle (e.g., shortened humerus, loss of 512 radial tuberosity, reduction/loss of hindlimbs, posterior migration of the blowhole, cranial 513 'telescoping') evolved convergently in odontocetes and mysticetes [1,102,103]. Morphological

514 characters preserved in fossils and pseudogenic remnants of formerly functional genes provide 515 complementary sources of evidence for elucidating such cases of convergent or parallel 516 evolution.

517 Finally, gene inactivation dates have important implications for understanding the 518 physiology, behavior, and appearance of extinct organisms [1,104]. In the case of cetaceans, 519 inactivation dates for AWAT1 and MOGAT3 are both older than the inactivation date for $520 A B C C 11$, which suggests that sebaceous glands were lost before sweat glands on the stem 521 cetacean branch. Given the timing of gene inactivations for these three genes, extinct protocetid 522 whales may have retained sweat glands but not sebaceous glands. Similarly, the hair inner root 523 sheath keratin KRT26 was lost relatively early on the stem cetacean branch ( 49 Ma), suggesting 524 that the program for generating body pelage hair had already been compromised at this early 525 stage in cetacean evolution. Protocetids, which comprise a paraphyletic grade, were probably the 526 earliest trans-oceanic cetaceans, but also spent time on land where they may have given birth and 527 nursed their young $[97,105,106]$. These forms would certainly have looked different than modern 528 whales due to their more prominent hindlimbs and primitive cranial morphology, but in other 529 respects, such as having a largely hairless body, may have been similar to modern cetaceans.

530 In summary, by integrating new histological data with comprehensive analyses of 531 molecular changes, we found strong support for the hypothesis that aquatic adaptations of the 532 skin evolved independently in hippos and cetaceans. Our study further illustrates the potential of 533 genomic data and in particular remnants of once functional genes as dateable 'molecular 534 vestiges' to complement morphological data in providing novel insights into ancestry and timing 535 of key trait changes and macroevolutionary transitions [68,86,96,104,107-111].

\section{Acknowledgments}

539 This work was supported by NSF grant DEB-1457735 (J.G., M.S.S.), NIH grants U01540 AR073159 and P30-AR075047 (M.V.P.), NSF grant DMS-1951144 (M.V.P.), and Pew 541 Charitable Trust LEO Foundation (M.V.P.). C.F.G-J. was supported by UC Irvine Chancellor's 
ADVANCE Postdoctoral Fellowship Program, NSF-Simons Postdoctoral Fellowship, NSF grant 543 (DMS1763272, to Qing Nie), Simons Foundation Grant (594598, to Qing Nie), and by a kind 544 gift from the Howard Hughes Medical Institute Hanna H. Gray Postdoctoral Fellowship 545 Program. M.H. was supported by the Max Planck Society and the LOEWE-Centre for 546 Translational Biodiversity Genomics (TBG) funded by the Hessen State Ministry of Higher 547 Education, Research and the Arts (HMWK). We thank the Smithsonian Institution for skin 548 samples of hippos. C. Buell provided images of mammals.

\section{References}

1. Gatesy, J., Geisler, J.H., Chang, J., Buell, C., Berta, A., Meredith, R.W., Springer, M.S., and McGowen, M.R. (2013). A phylogenetic blueprint for a modern whale. Mol. Phylogenet. Evol. 66(2), 479-506.

2. Springer, M.S., Signore, A.V., Paijmans, J.L.A., Vélez-Juarbe, J., Domning, D.P., Bauer, C.E.,

557 He, K., Crerar, L., Campos, P.F., Murphy, W.J., Meredith, R.W., Gatesy, J., Willerslev, E., 558 MacPhee, R.D.E., Hofreiter, M., and Campbell, K.L. (2015). Interordinal gene capture, the 559 phylogenetic position of Steller's sea cow based on molecular and morphological data, and the macroevolutionary history of Sirenia. Mol. Phylogenet. Evol. 91, 178-193.

3. Meredith, R.W., Gatesy, J., Emerling, C.A., York, V.M., Springer, M.S. (2013). Rod monochromacy and the coevolution of cetacean retinal opsins. PLoS Genet. 9(4), e1003432.

4. Flower, W.H., 1883. On whales, past and present, and their probable origin. Proc. R. Inst. Great Brit. 10, 360-376.

5. Slijper, E.J. (1962). Whales, second ed. Cornell University Press, Ithaca, NY. 
574 7. Harrison, R.J., and Thurley, K.W. (1974). Structure of the epidermis in Tursiops, Delphinus,

575 Orcinus and Phocoena. In: Harrison, R. (Ed.), Functional Anatomy of Marine Mammals, vol. 2.

576 Academic Press, London, pp. 45-72.

8. Ling, J. (1974). The integument of marine mammals. In: Harrison, R. (Ed.), Functional Anatomy of Marine Mammals, vol. 2. Academic Press, London, pp. 1-44.

9. Durham, F.E. (1980). External morphology of bowhead fetuses and calves. Mar. Fish. Rev. $42,74-80$.

10. Haldiman, J.T., Henk, W.G., Henry, R.W., Albert, T.F., Abdelbaki, Y.Z., and Duffield, D.W. mysticetus). Anat. Rec. 211(4), 391-402. bottlenose dolphin, Tursiops truncatus. J. Invest. Dermatol. 85, 60-63. calf (Eubalaena australis). J. Submicrosc. Cytol. Pathol. 28, 277-286.

594 13. Reeb, D., Best, P.B., and Kidson, S.H. (2007). Structure of the integument of southern right 595 whales, Eubalaena australis. Anat. Rec. 290, 596-613. 
604 16. Ehrlich F., Fischer, H., Langbein, L., Praetzel-Wunder, S., Ebner, B., Figlak, K., 605 Weissenbacher, A., Sipos, W., Tschachler, E., and Eckhart, L. (2019). Differential evolution of 606 the epidermal keratin cytoskeleton in terrestrial and aquatic mammals. Mol. Biol. Evol. 36, 328607340.

609 17. Sokolov, W. (1962). Adaptations of the mammalian skin to the aquatic mode of life. Nature 610 195(4840), 464-466.

612 18. Giacometti, L. (1967). The skin of the whale (Balaenoptera physalus). Anat. Rec, 159(1), $613 \quad 69-75$.

615 19. Geraci, J.R., Aubin, J., Hicks, B.D., Bryden, M.M., and Harrison, R. (1986). The epidermis 616 of odontocetes: a view from within. In Research on Dolphins, M.M. Bryden and R. Harrison, 617 eds., (Clarenden Press), pp. 3-21.

619 20. Menon, G.K., Grayson, S., Brown, B.E., and Elias, P.M. (1986). Lipokeratinocytes of the 620 epidermis of a cetacean (Phocena phocena). Cell Tissue Res. 244(2), 385-394.

622 21. Elias, P.M., Menon, G.K., Grayson, S., Brown, B.E., and Rehfeld, S.J. (1987). Avian 623 sebokeratocytes and marine mammal lipokeratinocytes: structural, lipid biochemical, and 624 functional considerations. Am. J. Anat. 180, 161-177.

626 22. Pfeiffer, C.J., and Jones, F.M. (1993). Epidermal lipid in several cetacean species: 627 ultrastructural observations. Anat. Embryol. 188, 209-218.

629 23. Meyer, W., Schmidt, J., Busche, R., Jacob, R., and Naim, H.Y. (2012). Demonstration of free 630 fatty acids in the integument of semi-aquatic and aquatic mammals. Acta Histochemica, 114(2), $631 \quad 145-150$. 
633 24. Lachner, J., Mlitz, V., Tschachler, E., and Eckhart, L. (2017). Epidermal cornification is 634 preceded by the expression of a keratinocyte-specific set of pyroptosis-related genes. Sci. Rep. $6357(1), 1-11$.

637 25. Parry, D.A. (1949). The structure of whale blubber, and a discussion of its thermal properties. Q. J. Microsc. Sci. 90, 13-25.

26. Palmer, E., and Weddell, G. (1964). The relationship between structure, innervation and 641 function of the skin of the bottle nose dolphin (Tursiops truncatus). Proc. Zool. Soc. Lond. 143. $642 \quad 553-568$.

27. Oh, J.W., Chung, O., Cho, Y.S., MacGregor, G.R., and Plikus, M.V. (2015). Gene loss in 645 keratinization programs accompanies adaptation of cetacean skin to aquatic lifestyle. Exp. 646 Dermatol. 24(8), 572-573.

28. Nakai, J., and Shida, T. (1948). Sinus-hairs of the sei-whale (Balaenoptera borealis). Sci. 649 Rept. Whales Res. Inst. 1, 41-47.

30. Ling, J.K. (1977). Vibrissae of marine mammals. In: Harrison, R.J. (Ed.), Functional

31. Berta, A., Ekdale, E.G., Zellmer, N.T., Demere, T.A., Kienle, S.S., and Smallcomb, M. (Cetacea, Mysticeti, Eschrichtiidae). Anat. Rec. 298, 648-659.

660 32. Drake, S.E., Crish, S.D., George, J.C., Stimmelmayr, R., and Thewissen, J.G. (2015). 661 Sensory hairs in the bowhead whale, Balaena mysticetus (Cetacea, Mammalia). Anat. Rec. 298, $662 \quad 1327-1335$. 
664 33. Yablokov, A.V., and Klevezal, G.A. (1969). Whiskers of whales and seals and their 665 distribution, structure and significance. In: Kleinenberg, S.E. (Ed.), Morphological 666 Characteristics of Aquatic Mammals. Izdatel'stvo Nauka, Moscow, Russia, pp. 48-81.

668 34. Czech-Damal, N.U., Liebschner, A., Miersch, L., Klauer, G., Hanke, F.D., Marshall, C., 669 Dehnhardt, G., and Hanke, W. (2012). Electroreception in the Guiana dolphin (Sotalia 670 guianensis). Proc. Roy. Soc. B 279, 663-668.

672 35. Huggenberger, S., Oelschläger, H., and Cozzi, B. (2019). Regional anatomy, development, 673 and hydrodynamics including skin anatomy. In: Huggenberger, S., Oelschläger, H., Cozzi, B. 674 (Eds.), Atlas of the Anatomy of Dolphins and Whales. Academic Press, pp. 5-135.

676 36. Boisserie, J.R., Fisher, R.E., Lihoreau, F., and Weston, E.M. (2011). Evolving between land 677 and water: key questions on the emergence and history of the Hippopotamidae 678 (Hippopotamoidea, Cetancodonta, Cetartiodactyla). Biol. Rev. 86(3), 601-625.

37. Allbrook, D.B., Luck, C.P., and Wright, P.G. (1959). Histological observations on the cutaneous glands in hippopotamus. J. Anat. 93, 587-588.

38. Allbrook, D. (1962). The morphology of the subdermal glands of Hippopotamus amphibius.

684 Proc. Zool. Soc. Lond. 139, 67-73.

39. Klećkowska-Nawrot, J.E., Goździewska-Harłajczuk, K., and Paszta, W. (2020). Gross 687 anatomy, histological and histochemical analysis of the eyelids and orbital glands of the neonate 688 pygmy hippopotamus (Suina: Choeropsis liberiensis or Hexaprotodon liberiensis, Morton 1849) 689 with reference to its habitat. Anat. Rec. 2020, 1-19.

691 40. Tomes, J. (1850). On the blood-coloured exudation from the skin of the hippopotamus. Proc. 692 Zool. Soc. Lond. 1850, 160-162. 
694 41. Saikawa, Y., Hashimoto, K., Nakata, M., Yoshihara, M., Nagai, K., Ida, M., and Komiya, T. 695 (2004). The red sweat of the hippopotamus. Nature 429, 363.

697 42. Prothero, D.R., Manning, E.M., and Fischer, M. (1988). The phylogeny of ungulates. In: 698 Benton, M.J. (Ed.), The Phylogeny and Classification Classification of the Tetrapods, Vol. 2. 699 Systematics Association Special Volume No. 35B. Clarendon Press, Oxford, pp. 201-234.

43. Novacek, M.J. (1992). Fossils, topologies, missing data, and the higher level phylogeny of eutherian mammals. Syst. Biol. 41, 58-73.

44. Matthew, W. D. (1929). Reclassification of the artiodactyl families. Bull. Soc. Amer. 40, 403-404.

45. Matthew, W.D., and Colbert, E.H. (1934). A phylogenetic chart of the Artiodactyla. J. Mammal. 15, 207-209.

46. Simpson, G.G. (1945). The principles of classification and a classification of mammals. Bull.

711 Amer. Mus. Nat. Hist. 85, 1-350.

47. Pickford, M. (1983). On the origins of Hippopotamidae together with descriptions of two

714 new species, a new genus and a new subfamily from the Miocene of Kenya. Geobios 16(2), 193715217.

717 48. Gentry, A.W., and Hooker, J.J. (1988). The phylogeny of the Artiodactyla. In: Benton, M.J.

718 (Ed.), The Phylogeny and Classification of the Tetrapods, Vol. 2: Mammals. Systematics 719 Association Special, Vol. 35B. Clarendon Press, Oxford, pp. 235-272.

721 49. Irwin, D., and Arnason, U. 1994. Cytochrome b gene of marine mammals: phylogeny and 722 evolution. J. Mammal. Evol. 2, 37-55. 
724 50. Shimamura, M., Yasue, H., Ohshima, K., Abe, H., Kato, H., Kishiro, T., Goto, M., 725 Munechika, I., and Okada, N. (1997). Molecular evidence from retroposons that whales form a 726 clade within even-toed ungulates. Nature, 388(6643), 666-670.

51. Gatesy, J., Hayashi, C., Cronin, A., Arctander, P. (1996). Evidence from milk casein genes that cetaceans are close relatives of hippopotamid artiodactyls. Mol. Biol. Evol. 13, 954-963.

52. Gatesy, J. (1997). More DNA support for a Cetacea/Hippopotamidae clade: the bloodclotting protein gene gamma-fibrinogen. Mol. Biol. Evol. 14, 537-543.

53. Gatesy, J. (1998). Molecular evidence for the phylogenetic affinities of Cetacea. In: Thewissen, J.G.M. (Ed.), The Emergence of Whales. Plenum, New York, pp. 63-111.

54. Nikaido, M., Rooney, A.P., and Okada, N. (1999). Phylogenetic relationships among cetartiodactyls based on insertions of short and long interspersed elements: hippopotamuses are the closest extant relatives of whales. Proc. Natl. Acad. Sci. USA 96, 10261-10266.

55. Geisler, J.H., and Theodor, J.M. (2009). Brief communications arising: hippo and whale phylogeny. Nature 458, E1-E4.

56. Spaulding, M., O'Leary, M.A., and Gatesy, J. (2009). Relationships of Cetacea (Artiodactyla) evolution. PLoS ONE 4(9), e7062.

57. O'Leary, M.A., and Gatesy, J. (2008). Impact of increased character sampling on the

749 phylogeny of Cetartiodactyla (Mammalia): combined analysis including fossils. Cladistics 24(4), $750 \quad 397-442$.

752 58. Clementz, M.T., Holroyd, P.A., and Koch, P.L. (2008). Identifying aquatic habits of 753 herbivorous mammals through stable isotope analysis. Palaios 23, 574-585. 
59. Zin-Maung-Maung-Thein, Takai, M., Uno, H., Wynn, J.G., Egi, N., Tsubamoto, T., Thaung-

Htike, Aung-Naing-Soe, Maung-Maung, Nishimura, T., and Yoneda, M. (2011). Stable isotope analysis of the tooth enamel of Chaingzauk mammalian fauna (late Neogene, Myanmar) and its implication to paleoenvironment and paleogeography. Palaeogeogr. Palaeoclimatol. Palaeoecol. 300, 11-22.

60. Lihoreau, F., Boisserie, J.R., Blondel, C., Jacques, L., Likius, A., Mackaye, H.T., Vignaud, P., and Brunet, M. (2014). Description and palaeobiology of a new species of Libycosaurus (Cetartiodactyla, Anthracotheriidae) from the late Miocene of Toros-Ménalla, northern Chad. J. Syst. Palaeontol. 12(7), 761-798.

61. Tütken, T., and Absolon, J. (2015). Late Oligocene ambient temperatures reconstructed by stable isotope analysis of terrestrial and aquatic vertebrate fossils of Enspel, Germany. Paleobiodivers. Paleoenviron. 95(1), 17-31.

62. Cooper, L.N., Clementz, M.T., Usip, S., Bajpai, S., Hussain, S.T., and Hieronymus, T.L. (2016). Aquatic habits of cetacean ancestors: integrating bone microanatomy and stable isotopes. Integr. Comp. Biol. 56, 1370-1384.

63. Soe, A.N., Chavasseau, O., Chaimanee, Y., Sein, C., Jaeger, J.J., Valentin, X., and Ducrocq, S. (2017). New remains of Siamotherium pondaungensis (Cetartiodactyla, Hippopotamoidea) from the Eocene of Pondaung, Myanmar: paleoecologic and phylogenetic implications. J.

777 Vertebr. Paleontol. 37(1), e1270290. M.F., and Rossiter, S.J. (2015). A phylogenomic analysis of the role and timing of molecular adaptation in the aquatic transition of cetartiodactyl mammals. Roy. Soc. Open Sci. 2(9), 150156. 
65. Strasser, B., Mlitz, V., Fischer, H., Tschachler, E. and Eckhart, L. (2015). Comparative genomics reveals conservation of filaggrin and loss of caspase-14 in dolphins. Exp. Dermatol. 24(5), 365-369.

66. Hecker, N., Sharma, V., and Hiller, M. (2017). Transition to an aquatic habitat permitted the repeated loss of the pleiotropic KLK8 gene in mammals. Genome Biol. Evol. 9(11), 3179-3188.

67. Sharma, V., Hecker, N., Roscito, J.G., Foerster, L., Langer, B.E., Hiller, M. (2018a). A genomics approach reveals insights into the importance of gene losses for mammalian adaptations. Nat. Comm. 9(1), 1-9.

68. Huelsmann, M., Hecker, N., Springer, M.S., Gatesy, J., Sharma, V., Hiller, M. (2019). Genes lost during the transition from land to water in cetaceans highlight genomic changes associated with aquatic adaptations. Sci. Adv. 5(9), eaaw6671.

69. Springer, M.S., and Gatesy, J. (2018). Evolution of the MC5R gene in placental mammals

800 with evidence for its inactivation in multiple lineages that lack sebaceous glands. Mol. 801 Phylogenet. Evol. 120, 364-374.

803 70. Lopes-Marques, M., Machado, A.M., Alves, L.Q., Fonseca, M.M., Barbosa, S., Sinding, 804 M.H.S., Rasmussen, M.H., Iversen, M.R., Frost Bertelsen, M., Campos, P.F., and Da Fonseca, 805 R.. (2019). Complete inactivation of sebum-producing genes parallels the loss of sebaceous 806 glands in Cetacea. Mol. Biol. Evol. 36(6), 1270-1280.

808 71. Montagna, W., and Yun, J. S. (1964). The skin of the domestic pig. J. Invest. Dermatol. 42, $80911-21$.

811 72. Mawafy, M., and Cassens, R. G. (1975). Microscopic structure of pig skin. J. Anim. Sci. 812 41(5), 1281-1290. 
814 73. Debeer, S., Le Luduec, J. B., Kaiserlian, D., Laurent, P., Nicolas, J.-F., Dubois, D., and

815 Kanitakis, J. (2013). Comparative histology and immunohistochemistry of porcine versus human

816 skin. Eur. J. Dermatol. 23(4), 456-466.

818 74. Abu-Samra, M.T., and Shuaib, Y.A. (2014). A study on the nature of association between

819 Demodex mites and bacteria involved in skin and meibomian gland lesions of demodectic mange

820 in cattle. Vet. Med. Int. 2014, 413719.

822 75. Jian, W., Duangjinda, M., Vajrabukka, C., and Katawatin, S. (2014). Differences of skin 823 morphology in Bos indicus, Bos taurus, and their crossbreds. Int. J. Biometeorol. 58(6), 10878241094.

826 76. Murgiano, L., Shirokova, V., Welle, M.M., Jagannathan, V., Plattet, P., Oevermann, A., 827 Pienkowska-Schelling, A., Gallo, D., Gentile, A., Mikkola, M., et al. (2015). Hairless streaks in 828 cattle implicate TSR2 in early hair follicle formation. PLoS Genet. 11(7), e1005427.

830 77. Turner, N.J., Pezzone, D., and Badylak, S.F. (2015). Regional variations in the histology of 831 porcine skin. Tissue Eng. Part C: Methods 21(4), 373-384.

833 78. Wiener, D.J., Wiedemar, N., Welle, M.M., and Drogemuller, C. (2015). Novel features of the 834 prenatal horn bud development in cattle (Bos taurus). PLoS One 10(5), e0127691.

836 79. Crespo-Moral, M., Garcia-Posadas, L., Lopez-Garcia, A., and Diebold, Y. (2020). 837 Histological and immunohistochemical characterization of the porcine ocular surface. PLoS One 838 15(1), e0227732.

840 80. Nakano, M., Miwa, N., Hirano, A., Yoshiura, K.I., and Niikawa, N. (2009). A strong 841 association of axillary osmidrosis with the wet earwax type determined by genotyping of the 842 ABCC11 gene. BMC Genetics 10(1), 42. 
844 81. Martin, A., Saathoff, M., Kuhn, F., Max, H., Terstegen, L., and Natsch, A. (2010). A

845 functional $\mathrm{ABCC} 11$ allele is essential in the biochemical formation of human axillary odor. J.

846 Invest. Dermatol. 130(2), 529-540.

848 82. Sharma, V., Hecker, N., Walther, F., Stuckas, H., and Hiller, M. (2020). Convergent losses of

849 TLR5 suggest altered extracellular flagellin detection in four mammalian lineages. Mol. Biol.

850 Evol. 37, 1847-1854.

83. Yamakoshi, T., Makino, T., Ur Rehman, M., Yoshihisa, Y., Sugimori, M., and Shimizu, T. (2013). Trichohyalin-like 1 protein, a member of fused S100 proteins, is expressed in normal and 854 pathologic human skin. Biochem. Biophys. Res. Comm. 432, 66-72.

84. Makino, T., Mizawa, M., Yoshihisa, Y., and Shimizu, T. (2019). Ultraviolet B irradiation increases the expression of trichohyalin-like 1 protein in human skin xenotransplants. Clin. Exp. Dermatol. 44, 773-776.

85. Abbas Zadeh, S., Mlitz, V., Lachner, J., Golabi, B., Mildner, M., Pammer, J., Tschachler, E., and Eckhart, L. (2017). Phylogenetic profiling and gene expression studies implicate a primary role of PSORS1C2 in terminal differentiation of keratinocytes. Exp. Dermatol. 26, 352-358.

86. Sharma, V., Lehmann, T., Stuckas, H., Funke, L., and Hiller, M. (2018b). Loss of RXFP2 and INSL3 genes in Afrotheria shows that testicular descent is the ancestral condition in placental mammals. PLoS Biol. 16(6), e2005293.

87. Kong, W., Longaker, M.T., and Lorenz, H.P. (2003). Molecular cloning and expression of

869 keratinocyte proline-rich protein, a novel squamous epithelial marker isolated during skin 870 development. J. Biol. Chem. 278, 22781-22786.

872 88. Lee, W.H., Jang, S., Lee, J.S., Lee, Y., Seo, E.Y., You, K.H., Lee, S.C., Nam, K.I., Kim, 873 J.M., Kee, S.H., et al. (2005). Molecular cloning and expression of human keratinocyte proline- 
874 rich protein (hKPRP), an epidermal marker isolated from calcium-induced differentiating 875 keratinocytes. J. Invest. Dermatol. 125, 995-1000. 89. Suga, H., Oka, T., Sugaya, M., Sato, Y., Ishii, T., Nishida, H., Ishikawa, S., Fukayama, M., 878 and Sato, S. (2019). Keratinocyte proline-rich protein deficiency in atopic dermatitis leads to barrier disruption. J. Invest. Dermatol. 139, 1867-1875.

90. Serhan, C.N., Chiang, N., and Van Dyke, T.E. (2008). Resolving inflammation: dual antiinflammatory and pro-resolution lipid mediators. Nat. Rev. Immunol. 8, 349-361.

91. Spite, M., Norling, L.V., Summers, L., Yang, R., Cooper, D., Petasis, N.A., Flower, R.J., Perretti, M., and Serhan, C.N. (2009). Resolvin D2 is a potent regulator of leukocytes and controls microbial sepsis. Nature 461, 1287-1291.

92. Kim, S.N., Akindehin, S., Kwon, H.J., Son, Y.H., Saha, A., Jung, Y.S., Seong, J.K., Lim, K.M., Sung, J.H., Maddipati, K.R., et al. (2018). Anti-inflammatory role of 15-lipoxygenase contributes to the maintenance of skin integrity in mice. Sci. Rep. 8, 8856.

93. Nery, M.F., Arroyo, J.I., and Opazo, J.C. (2014). Increased rate of hair keratin gene loss in the cetacean lineage. BMC Genomics 15, 869.

896 dimensional CT examination of the forefoot and hindfoot of the hippopotamus and tapir during a 897 semiaquatic walking. Anat. Histol. Embryol. 48(1), 3-11.

95. Kranz, K.R. (1982). A note on the structure of tail hairs from a pygmy hippopotamus

900 (Choeropsis liberiensis). Zoo Biol. 1, 237-241.

902 96. Meredith, R.W., Gatesy, J., Murphy, W.J., Ryder, O.A., and Springer, M.S. (2009).

903 Molecular decay of the tooth gene enamelin (ENAM) mirrors the loss of enamel in the fossil 904 record of placental mammals. PLoS Genet. 5(9), e1000634. 
906 97. Thewissen, J.G.M., Cooper, L.N., George, J.C., and Bajpai, S. (2009). From land to water:

907 the origin of whales, dolphins, and porpoises. Evo. Edu. Outreach, 2(2), 272-288.

909 98. Thewissen, J.G.M., Cooper, L.N., Clementz, M.T., Bajpai, S., and Tiwari, B.N. (2007).

910 Whales originated from aquatic artiodactyls in the Eocene epoch of India. Nature 450, 11909111194.

913 99. Boisserie, J.R., Zazzo, A., Merceron, G., Blondel, C., Vignaud, P., Likius, A., Mackaye, 914 H.T., and Brunet, M. (2005). Diets of modern and late Miocene hippopotamids: evidence from 915 carbon isotope composition and micro-wear of tooth enamel. Palaeogeogr. Palaeoclimatol. 916 Palaeoecol. 221(1-2), 153-174.

918 100. Wolsan, M., and Sato, J.J. (2020). Parallel loss of sweet and umami taste receptor function 919 from phocids and otarioids suggests multiple colonizations of the marine realm by pinnipeds. J. 920 Biogeogr. 47, 235-249.

922 101. Paterson, R. S., Rybczynski, N., Kohno, N., and Maddin, H. C. (2020). A total evidence 923 phylogenetic analysis of pinniped phylogeny and the possibility of parallel evolution within a 924 monophyletic framework. Front. Ecol. Evol. 7, 457.

926 102. Geisler, J.H., and Sanders, A. E. (2003). Molecular evidence for the phylogeny of Cetacea. 927 J. Mamm. Evol. 10, 23-27.

929 103. Boessenecker, R. W., Churchill, M., Buchholtz, E. A., Beatty, B. L., and Geisler, J. H. 930 (2020). Convergent evolution of swimming adaptations in modern whales revealed by a large 931 macrophagous dolphin from the Oligocene of South Carolina. Curr. Biol. 30, 1-7.

933 104. Springer, M.S., and Gatesy, J. (2017). Inactivation of the olfactory marker protein (OMP) 934 gene in river dolphins and other odontocete cetaceans. Mol. Phylogenet. Evol. 109, 375-387. 
936 105. Geisler, J. (2019). Whale evolution: dispersal by paddle and fluke. Curr. Biol. 29, R280937 R299.

939 106. Lambert, O., Bianucci, G., Salas-Gismondi, R., Di Celma, C., Steurbaut, E., Urbina, M., 940 and de Muizon, C. (2019). An amphibious whale from the middle Eocene of Peru reveals early

941 South Pacific dispersal of quadrupedal cetaceans. Curr. Biol. 29, 1352-1359.

943 107. Meredith, R.W., Zhang, G., Gilbert, M.T.P., Jarvis, E.D., Springer, M.S. (2014). Evidence

944 for a single loss of mineralized teeth in the common avian ancestor. Science 346, 6215.

946 108. Springer, M.S., Emerling, C.A., Fugate, N., Patel, R., Starrett, J., Morin, P.A., Hayashi, C., 947 and Gatesy, J. (2016). Inactivation of cone-specific phototransduction genes in rod 948 monochromatic cetaceans. Front. Ecol. Evol. 4, 61.

950 109. Springer, M.S., Starrett, J., Morin, P.A., Lanzetti, A., Hayashi, C., and Gatesy, J. (2016). 951 Inactivation of C4orf26 in toothless placental mammals. Mol. Phylogenet. Evol. 95, 34-45.

953 110. Gaudry, M.J., Jastroch, M., Treberg, J.R., Hofreiter, M., Paijmans, J.L., Starrett, J., Wales,

954 N., Signore, A.V., Springer, M.S., and Campbell, K.L. (2017.) Inactivation of thermogenic $955 U C P 1$ as a historical contingency in multiple placental mammal clades. Sci. Adv. 3(7), 956 e1602878.

958 111. Jebb, D., and Hiller, M. (2018). Recurrent loss of HMGCS2 shows that ketogenesis is not 959 essential for the evolution of large mammalian brains. Elife 7, e38906.

961 112. Sharma, V., and Hiller, M. (2017). Increased alignment sensitivity improves the usage of 962 genome alignments for comparative gene annotation. Nuc. Acids Res. 45(14), 8369-8377.

964 113. Meyer, W.K., Jamison, J., Richter, R., Woods, S.E., Partha, R., Kowalczyk, A., Kronk, C., 965 Chikina, M., Bonde, R.K., Crocker, D.E., and Gaspard, J. (2018). Ancient convergent losses of 
968 114. Zerbino, D.R., Achuthan, P., Akanni, W., Amode, M.R., Barrell, D., Bhai, J., Billis, K.,

969 Cummins, C., Gall, A., Girón, C.G., et al. (2018). Ensembl 2018. Nuc. Acids Res. 46(D1),

970 D754-D761.

971

972 115. Kearse, M., Moir, R., Wilson, A., Stones-Havas, S., Cheung, M., Sturrock, S., Buxton, S.,

973 Cooper, A., Markowitz, S., Duran, C., Thierer, T., Ashton, B., Mentjies, P., and Drummond, A.

974 (2012). Geneious basic: an integrated and extendable desktop software platform for the

975 organization and analysis of sequence data. Bioinformatics 28, 1647-1649.

976

977 116. Katoh, K., and Standley, D.M. (2013). MAFFT multiple sequence alignment software

978 version 7: improvements in performance and usability. Molecular biology and evolution, 30, $979772-780$.

981 117. Swofford D.L. (2002). PAUP*: phylogenetic analysis using parsimony (*and other 982 methods). $4.0 \mathrm{~b} 10$ ed. Sunderland (Massachusetts): Sinauer Associates, Inc.

984 118. Stamatakis, A., Ludwig, T., and Meier, H. (2005). RAxML-III: a fast program for 985 maximum likelihood-based inference of large phylogenetic trees. Bioinformatics 21(4), pp.456986463.

988 119. Schull J.K., Turakhia Y., Dally W.J., and Bejerano G. (2019). Champagne: Whole-genome 989 phylogenomic character matrix method places Myomorpha basal in Rodentia. bioRxiv 803957.

991 120. Yang, Z., 2007. PAML 4: phylogenetic analysis by maximum likelihood. Mol. Biol. Evol. $992 \quad 24,1586-1591$.

994 121. Meredith, R.W., Janecka, J.E., Gatesy, J., Ryder, O.A., Fisher, C.A., Teeling, E.C., 995 Goodbla, A., Eizirik, E., Simão, T.L.L., Stadler, T., Rabosky, D.L., Honeycutt, R.L., Flynn, J.J., 996 Ingram, C.M., Steiner, C., Williams, T.L., Robinson, T.J., Burk-Herrick, A., Westerman, M., 
Ayoub, N.A., Springer, M.S., and Murphy, W.J. (2011). Impacts of the Cretaceous terrestrial revolution and KPg extinction on mammal diversification. Science 334, 521-524. timing of diversification of Cetartiodactyla (Mammalia, Laurasiatheria), as revealed by a comprehensive analysis of mitochondrial genomes. Comptes Rendus Biologies 335, 32-50. Phylogenomic resolution of the cetacean tree of life using target sequence capture. Syst. Biol. 69, 479-501.

124. Sandby-Moller, J., Poulsen, T., and Wulf, H.C. (2003). Epidermal thickness at different body sites: relationship to age, gender, pigmentation, blood content, skin type and smoking 1012 habits. Acta Derm. Venereol. 83(6), 410-413.

1015 M.R., Legesse, T., Drachenberg, C.B., Manson, P.N., and Christy, M.R. (2015). A 1016 comprehensive examination of topographic thickness of skin in the human face. Aesthet. Surg. J. 1017 35(8), 1007-1013.

1019 126. Hole, M.B., Bhosle, N.S., and Kapadnis, P.J. (2008). Study of hair follicles in red kandhari 1020 cows. Indian J. Animal Res. 42(2), 151-152.

\section{STAR Methods}

\section{Skin Sample Collection}

1025 The sources for skin samples used in histological analyses are as follows: Choeropsis liberiensis 1026 (pygmy hippopotamus) skin samples are from Smithsonian National Museum of Natural History 1027 - specimen number 395848 (unknown gender, neonatal); Hippopotamus amphibius (river 
1028 hippopotamus) skin samples are from Smithsonian National Museum of Natural History 1029 specimen number 254870 (male, neonatal); Tursiops truncatus (common bottlenose dolphin) 1030 skin samples are from Southwest Fisheries Science Center (NOAA) specimen numbers 1031 KKS0032 (unknown gender, neonatal) and KXD0206 (late term fetus); Eschrichtius robustus 1032 (gray whale) skin samples are from Southwest Fisheries Science Center (NOAA) Fisheries 1033 specimen number NEB0083 (unknown gender, adult).

1034

1035 Histology

1036 Formalin-fixed Choeropsis liberiensis and Hippopotamus amphibius skin samples were first

1037 hydrated and rinsed in 1X PBS. Samples were then dehydrated through an ethanol gradient (from $103825 \%$ to $100 \%$ ), processed through histoclear and embedded in paraffin. Each hydration and 1039 dehydration step lasted for 12 hours. Tissues were sectioned at a thickness of $10 \mu \mathrm{m}$ with a 1040 microtome (Leica). Samples were stained with hematoxylin and eosin using standard methods 1041 with minor modifications. Tissue sections were mounted with Permount mounting media and 1042 visualized with Nikon Ti-E Upright microscope. Tissue whole-mounts were captured with a 1043 Nikon dissecting microscope. Individual fields of Eschrichtius robustus rostral skin were 1044 visualized and stitched together with Keyence microscope.

1046 Quantification of Epidermal Thickness

1047 Epithelial thickness of Choeropsis liberiensis, Hippopotamus amphibius, Tursiops truncatus and 1048 Eschrichtius robustus rostral skin was quantified using ImageJ (NIH). We included 1049 measurements ranging from: a) top to start of rete ridge; b) start to end of rete ridge; and c) entire 1050 epidermis including rete ridge. Up to 10 individual measurements were included per image field 1051 per species. Measurements are reported as average epidermal thickness $(\mu \mathrm{m}) \pm$ standard 1052 deviation $(\mu \mathrm{m})$ in Table 1.

1053

1054 Pygmy Hippopotamus Genome

1055 Genomic DNA from Choeropsis liberiensis (pygmy hippopotamus) was provided by G. Amato 1056 (formerly at New York Zoological Society). DNA was sonicated at the University of California, 1057 Riverside (UCR), Genomics Core Facility into 550 bp fragments. We constructed a genomic 
1058 library using Illumina's NeoPrep Library Prep System. Paired-end sequencing (150 bp) was

1059 performed at UCR. Raw reads have been deposited at NCBI (accession XXXXXXXX).

1060

1061 Genomic Screens for Inactivated Genes

1062 We used a genome alignment of placental mammals with the human hg38 assembly as the 1063 reference [112] and gene loss data generated by our gene loss detection method [68,113] to 1064 screen for genes that exhibit inactivating mutations in the genomes of bottlenose dolphin, killer 1065 whale, sperm whale, common minke whale, and river hippo. We started with 19,769 genes 1066 annotated by Ensembl (http://www.ensembl.org) version 90 [114] in the human genome and 1067 considered 18,363 genes that are present in the assemblies of at least 31 of 63 placental 1068 mammals. To identify genes that were potentially inactivated on the branch leading to hippos 1069 and cetaceans, we further extracted genes that are inactivated in all cetaceans and the river hippo. 1070 We excluded genes that are intact in less than three of six terrestrial outgroup artiodactyls 1071 included in the screen (Bos taurus [cow], Capra hircus [goat], Camelus ferus [wild Bactrian 1072 camel], Pantholops hodgsonii [Tibetan antilope], Bison bison [bison], Vicugna pacos [alpaca]). 1073 Finally, we used a more recent assembly of the river hippo genome (GCA_004027065.2) to 1074 exclude instances where assembly errors mistakenly led to genes classified as inactivated in the 1075 river hippo. This resulted in a final list of 38 genes (Supplemental Table S1).

\section{BLAST Searches, Alignments, and Inactivating Mutations}

1078 Genomic sequences encoding ten genes of interest (ABCC11, ALOX15, AWAT1, KPRP, KRT2, 1079 KRT26, KRT77, KRTAP7-1, MOGAT3, TCHHL1) were downloaded from NCBI for Homo 1080 sapiens (human), Bos taurus (cow), and Equus caballus (horse). Sequences for each gene were 1081 aligned and exon annotations in Bos and Equus were compared against those in Homo to ensure 1082 that orthologous regions were annotated. Protein-coding sequences and flanking introns from 1083 Bos and Equus were employed in BLAST searches against other cetartiodactyls and 1084 perissodactyls, respectively, in NCBI's 'RefSeq Genome' and 'Whole-genome shotgun contigs' 1085 databases. Additional perissodactyls included Ceratotherium simum (white rhinoceros) and 1086 Dicerorhinus sumatrensis (Sumatran rhinoceros). Additional cetartiodactyls included two 1087 camelids (Camelus ferus [wild Bactrian camel], Vicugna pacos [alpaca]), one suid (Sus scrofa 1088 [pig]), two bovids (Bubalus bubalis [water buffalo], Capra hircus [goat]), two giraffids (Giraffa 
1089 camelopardalis [giraffe], Okapia johnstoni [okapi]), two cervids (Axis porcinus [hog deer],

1090 Odocoileus virginianus [white-tailed deer]), one hippopotamid (Hippopotamus amphibius [river

1091 hippopotamus]), four mysticetes (Balaena mysticetus [bowhead, downloaded from

1092 http://www.bowhead-whale.org/], Balaenoptera acutorostrata [common minke whale], $B$.

1093 bonaerensis [Antarctic minke whale], Eschrichtius robustus [gray whale]), and ten odontocetes

1094 (Physeter macrocephalus [sperm whale], Lipotes vexillifer [baiji], Delphinapterus leucas

1095 [beluga], Phocoena phocoena [harbor porpoise], Neophocaena asiaorientalis [narrow-ridged

1096 finless porpoise], Orcinus orca [killer whale], Lagenorhynchus obliquidens [Pacific white-sided

1097 dolphin], Sousa chinensis [Indo-Pacific humpback dolphin], Tursiops aduncus [Indo-Pacific

1098 bottlenose dolphin], Tursiops truncatus [common bottlenose dolphin]). Additional searches were

1099 performed with other perissodactyls or cetartiodactyls when the initial searches with Equus and

1100 Bos were unsuccessful in retrieving complete orthologs. Megablast was employed for highly

1101 similar sequences and blastn for less similar sequences. Complete protein-coding sequences and

1102 intervening introns were imported into Geneious 11.1.5 [115] and aligned against reference

1103 sequences with MAFFT [116] with minor adjustments by eye. Aligned sequences were

1104 annotated for exons and inspected for splice site mutations. Illumina sequences for Choeropsis

1105 liberiensis were imported into Geneious and protein-coding sequences for the above-mentioned

1106 genes were obtained using a map to reference approach with probe sequences from the closely

1107 related Hippopotamus amphibius. We allowed for a maximum mismatch of 6\% per read and

1108 required at least two reads for base calling with a consensus threshold of $65 \%$. We also used

1109 MAFFT to align complete protein-coding sequences from all taxa for each gene.

\section{Inactivating Mutations}

1112 Final alignments for protein-coding sequences for each gene included 15-29 taxa given that some

1113 genes are deleted in one or more cetaceans. We inspected the final protein-coding alignment for

1114 each gene for inactivating mutations including exon deletions, frameshift insertions and 1115 deletions, altered start and stop codons, and premature stop codons (splice site mutations 1116 screened above). Parsimony optimizations with delayed transformation (deltran) were performed 1117 with PAUP* 4.0a150 [117] to map inactivating mutations to branches of the species tree (see 1118 below) for each gene. 


\section{Phylogenetic Analyses}

1121 RAxML 8.2.11 [118] was run in Geneious to estimate maximum likelihood gene trees for each 1122 protein-coding alignment. Gene trees were inspected for suspicious relationships that conflict 1123 with the species tree (e.g., Camelus grouping with Sus instead of Vicugna) but none were found.

1124 Instead, gene tree incongruence was confined to conflicts that are readily explained by ILS such 1125 as Ruminantia grouping with Suoidea or Physeter grouping with Mysticeti [119]. Rapid 1126 bootstrap analysis (100 pseudoreplications) and a search for the best tree were performed in a 1127 single run. These analyses were performed with a GTR $+\Gamma$ model of sequence evolution.

\section{DN/dS Analyses}

$1130 \mathrm{DN} / \mathrm{dS}$ analyses were performed with the codeml program of PAML 4.4 [120]. Analyses for 1131 each gene were performed with separate $\mathrm{dN} / \mathrm{dS}$ categories for functional branches that lack 1132 inactivating mutations, fully pseudogenic branches that post-date the occurrence of an 1133 inactivating mutation on an earlier branch, and each transitional branch that records the first 1134 occurrence of an inactivating mutation (e.g., [96]). Analyses were performed with the codon 1135 frequency 1 (CF1) and codon frequency 2 (CF2) models of codeml. We also performed analyses 1136 with estimated and fixed $(\mathrm{dN} / \mathrm{dS}=1.00)$ values for the fully pseudogenic branch category. We 1137 employed a species tree with higher level (interordinal, interfamilial) relationships from 1138 Meredith et al. [121] and intrafamilial relationships from Hassanin et al. [122] for terrestrial 1139 cetartiodactyls and McGowen et al. [123] for cetancodontans.

\section{Estimation of Gene Inactivation Times}

1142 Equations from Meredith et al. [96] were used to estimate gene inactivation times in 1143 hippopotamids and cetaceans. We performed calculations using eight different combinations of 1144 codon model (CF1 or CF2), fixed (1.0) versus estimated values for $\mathrm{dN} / \mathrm{dS}$ on fully pseudogenic 1145 branches, and equations that allow for one versus two synonymous substitution rates [96]. Mean 1146 inactivation dates for each gene are averages based on these eight different combinations. 1147 Divergence times for relevant nodes in these calculations were taken from McGowen et al. [123].

\section{Supplemental Tables}

1150

1151 Table S1. List of genes that are inactivated in cetaceans and hippopotamids. 
1152 Table S2. Inactivating mutations in cetaceans and hipppotamids.

1153 Table S3. Estimated inactivation dates for pseudogenized skin genes.

\section{Figure Legends}

1157 Figure 1. Two hypotheses for the evolution of aquatic adaptations in hippopotamids and 1158 cetaceans. (A) Evolution of shared aquatic features in the common ancestor of Hippopotamidae 1159 and Cetacea, and (B) independent evolution of aquatic features on the cetacean stem lineage and 1160 also on the hippopotamid stem lineage. Encircled red stars mark the initial evolution of 1161 behavioral, physiological, and anatomical characteristics associated with adaptation to aquatic 1162 environments. Aquatic (blue) and terrestrial (brown) specializations of extant taxa (squares) and 1163 ancestral nodes (circles) are indicated in each scenario.

1165 Figure 2. Histological features of the skin in hippos (A-D) and cetaceans (E-G). (A) Whole 1166 mount (left) and histological appearance (middle, right) of the upper lip skin in pigmy hippo. In

1167 the lip, vibrissa hairs above the skin surface and anagen (active growth) phase vibrissa hair 1168 follicles are prominent. On histology, each lip vibrissa follicle has a prominent mesenchymal 1169 dermal papilla (black arrowhead, center), a collagen capsule (white arrowheads, center), an 1170 epithelial matrix, a mesenchymal ringwulst (black arrowheads, right), and an epithelial bulge 1171 (white arrowheads, right). There is no histological evidence of sebaceous glands. (B) Whole 1172 mount of tail skin from pygmy hippo (left) shows large hair follicles (white bracket). 1173 Histological analysis (right) suggests that tail hair follicles might be of vibrissa type because they 1174 are surrounded by a collagen capsule (white arrowheads). There is no histological evidence of 1175 sebaceous glands. (C, D) Whole mount and corresponding histological view of upper lip skin (C) 1176 and dorsal skin (D) in the pigmy hippo. At both sites, eccrine sweat glands are present. On 1177 histology, secretory coils located deep in the dermis are marked with black arrowheads; 1178 associated excretory ducts (where obvious) are marked with white arrowheads. In the dorsal skin 1179 (D), secretory coils of the glands reside at the very base of the dermis and come in contact with 1180 the underlying skeletal muscle layer. There is no histological evidence of dermal adipocytes. (E) 1181 Histology of facial skin and a rostral vibrissa hair follicle in an adult gray whale. The epidermis 1182 is thick and its basal layer is heavily undulated. The vibrissa follicle has a typical anagen (active 1183 growth) phase morphology with a large mesenchymal dermal papilla (green arrowheads, second 
1184 panel) surrounded by epithelial matrix (yellow arrowheads, second panel). The epithelial outer 1185 root sheath compartment located above hair matrix is uncharacteristically thick and has 1186 prominent protrusions (yellow arrowheads, third panel). The vibrissa follicle is associated with 1187 distinct nerve bundles on either side (yellow arrowheads, fourth panel). (F) Wholemount side 1188 view of rostral skin from neonatal common bottlenose dolphin. Vibrissae hairs (black 1189 arrowheads) are clearly visible above the skin surface. (G) Histological view of rostral vibrissa 1190 hair follicle from neonatal common bottlenose dolphin. The vibrissa follicle has anagen phase 1191 morphology. A large dermal papilla (green arrowheads, bottom middle panel) and an 1192 uncharacteristically thin epithelial matrix (yellow arrowheads, bottom middle panel) are obvious. 1193 Unlike in gray whale, the outer root sheath lacks undulations, and like in gray whale, the vibrissa 1194 follicle lacks sebaceous gland. The overlaying epidermis displays prominent rete ridges (yellow 1195 arrowheads, right panel). The surrounding dermis contains numerous adipocyte clusters (blue 1196 arrowheads, right panel). Scale bar: A-E, G- $50 \mu \mathrm{m}$.

1198 Figure 3. Inactivating mutations in KRTAP7-1 (A) and $A B C C 11$ (B). Genes are shown with 1199 exons represented by green rectangles proportional to their size and introns represented by 1200 horizontal lines. Inactivating mutations are premature stop codons (vertical black line and 1201 corresponding triplet), insertions (red arrowhead and corresponding insertion size), deletions 1202 (vertical red line and corresponding deletion size, or red rectangle for completely deleted exon), 1203 and splice site donor or acceptor mutations (red letters at the end or beginning of an exon, 1204 respectively). Insets show the DNA sequence context of representative mutations. See 1205 supplementary alignment files for inactivating mutations in other genes. (C) The phylogenetic 1206 pattern of skin gene inactivations mapped onto a timetree for Cetancodonta (Hippopotamidae + 1207 Cetacea). Independent inactivations of skin genes (red triangles) are marked on branches of the 1208 tree; inactivation times are average estimates for each locus based on $\mathrm{dN} / \mathrm{dS}$ analyses. The mean 1209 dates of skin gene knockouts for six loci that were inactivated in the common ancestor of 1210 Cetacea and for eight loci that were inactivated in the common ancestor of Hippopotamidae are 1211 indicated on the stem lineages to these clades (encircled red stars). The timetree for extant 1212 lineages is based on the molecular clock analysis of McGowen et al. [123]. Extinct lineages for 1213 stem cetaceans (Indohyus, Ambulocetus, Georgiacetus) and stem hippopotamids (Elomeryx, 1214 Libycosaurus) are approximately positioned relative to the geological time scale based on earliest 
1215 occurrence in the fossil record for each genus and phylogenetic hypotheses based on 1216 morphological characters.

1218 Figure 4. Gene tree for MOGAT3 that shows inferred gene duplication event in Hippopotamidae 1219 (yellow circle) and parallel gene inactivations (red lineages). Seven gene knockouts are inferred, 1220 including pseudogenization of the MOGAT3 paralog that was derived from a duplication event 1221 on the stem hippopotamid branch. Lineages with functional MOGAT3 are gray, and lineages 1222 with inactivated MOGAT3 are colored red. Branches where inactivation events (frameshift 1223 indels, premature stop codons) were inferred by parsimony optimization of indels are gray and 1224 red, indicating the transition from functional to non-functional. The dashed red lineage for 1225 Choeropsis liberiensis represents hypothesized deletion of the MOGAT3 paralog in the genome of this species. Branch lengths are in expected numbers of substitutions per site.

Figure 5. A comparison of skin structures in human, hippo, and dolphin with skin-associated gene inactivation in hippopotamids and cetaceans. A) Schematic drawing of Homo sapiens skin.

1230 Key anatomical structures, including multi-layered epidermis, dermis, dermal white adipose 1231 tissue (dWAT), subcutaneous white adipose tissue (sWAT), and ectodermal appendages (hair 1232 follicles with sebaceous glands and sweat glands) are shown and color-coded. The epidermis 1233 (middle panel) is divided into stratum basale - which houses stem cells, and suprabasal layers of 1234 differentiating cells that include stratum spinosum, stratum granulosum, and stratum corneum. 1235 dWAT is closely associated with growing hair follicles and secretory coils of sweat glands. 1236 Additional abbreviations: IRS - inner root sheath; ORS - outer root sheath; DP - dermal papilla; 1237 Mx - hair matrix; SCs - stem cells. (B) Schematic of "average" hippo skin. The epidermis is 1238 relatively thin in comparison to cetaceans and displays shallow rete ridges. The dermis lacks 1239 identifiable adipocytes. Ventral, dorsal and ear skin contains pelage hair follicles that lack 1240 associated sebaceous glands. Facial skin features vibrissae follicles that also lack sebaceous 1241 glands. Tail skin contains prominent hair follicles that have vibrissa-like morphology. Several 1242 body sites contain distinct sweat glands. (C) Schematic drawing of facial skin in common 1243 bottlenose dolphin. The epidermis is very thick and features prominent rete ridges. The dermis 1244 contains numerous adipocyte clusters. In newborn dolphin, the facial skin contains actively 1245 growing vibrissae hair follicles that lack distinct collagen capsules, ringwulst, and sebaceous 
1246 glands (left). In adult dolphin, facial vibrissae degrade, forming keratin-filled pits (right). Skin 1247 has no sweat glands. (D) Skin-associated genes (excluding KRTAP genes) that are inactivated in 1248 some or all cetaceans and sometimes in hippos (see main text). Genes are classified based on 1249 their cell type or skin structure-specific expression and ontology as projected on the human skin 1250 diagram in A. Genes in black font are inactivated in some (*) or all cetaceans but not in hippos; 1251 genes in red font are independently inactivated in some (*) or all cetaceans and both hippos; the 1252 single gene in blue font is independently inactivated in cetaceans and pygmy hippo. Inactivated 1253 genes are based on the literature [16,24,65-67,69,70,85] and new observations reported here. 


\section{A Shared aquatic ancestry}

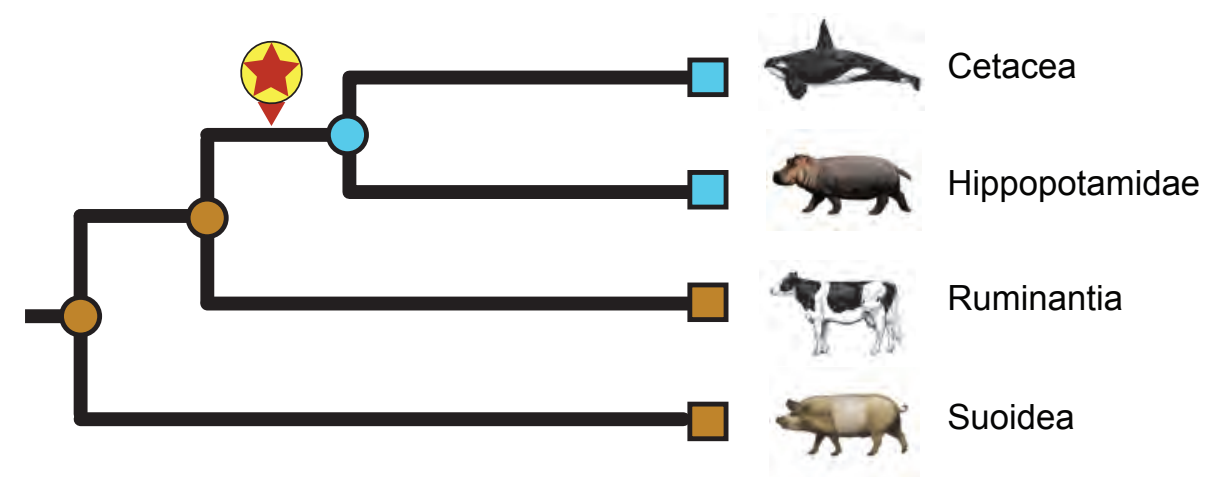

B Independent aquatic evolution

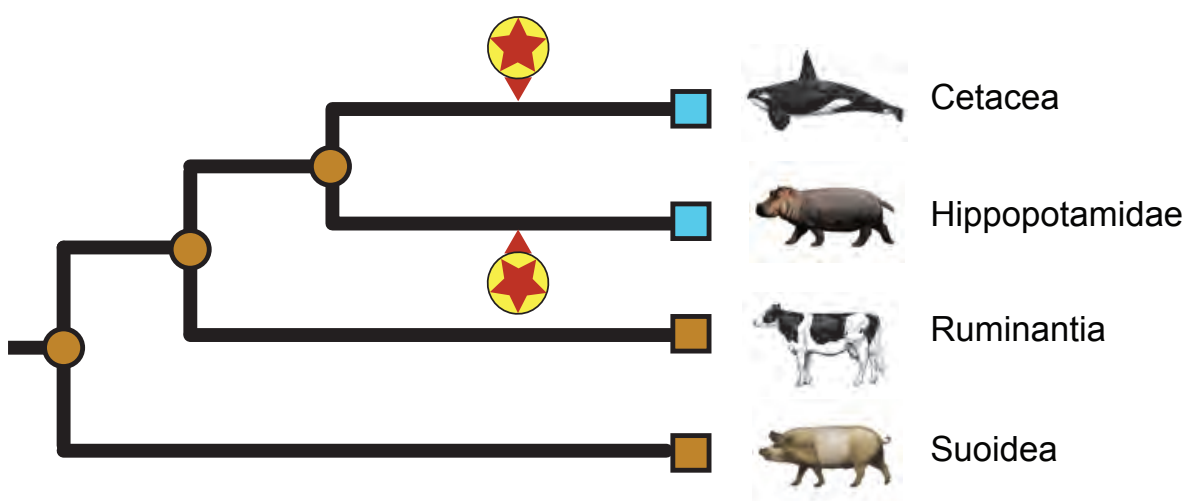


A Choeropsis liberiensis

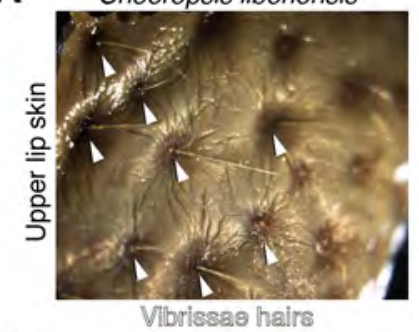

B

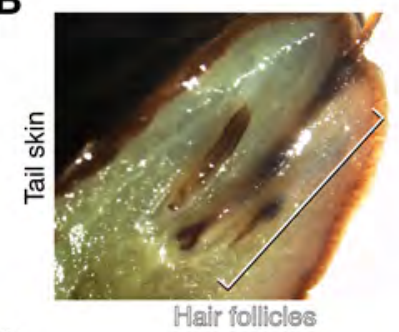

C

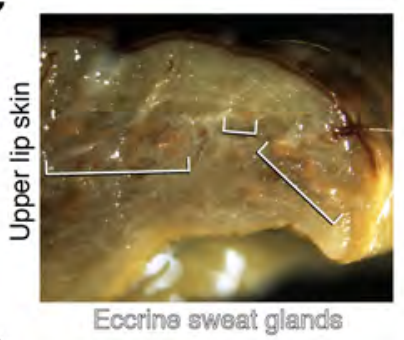

D

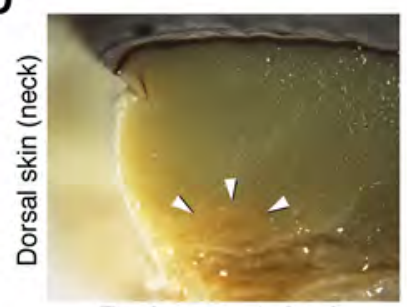

Eccrine sweat gland
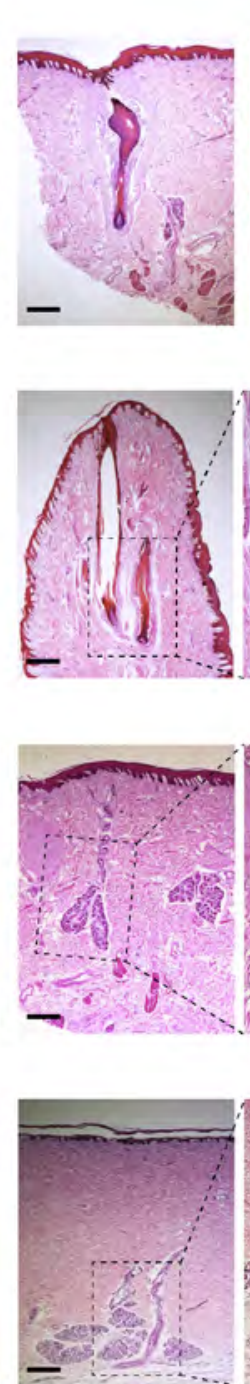

Vibrissa hair follicle

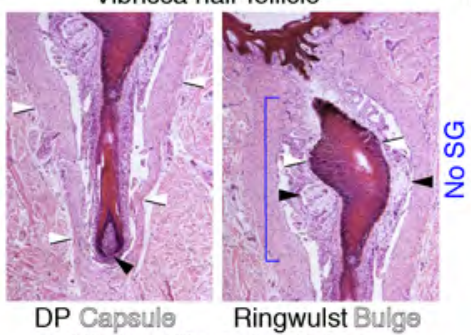

DP Capsule Ringwulst Bulgø

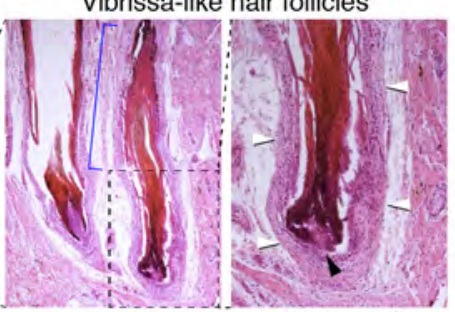

No SG

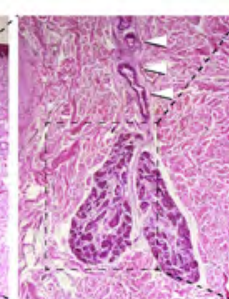

DP Capsule

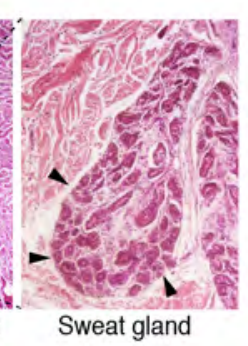

Sweat gland duct Sweat gland

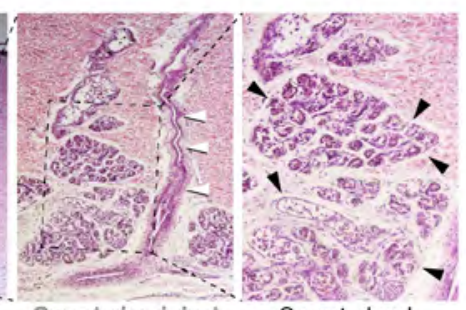

E Eschrichtius robustus

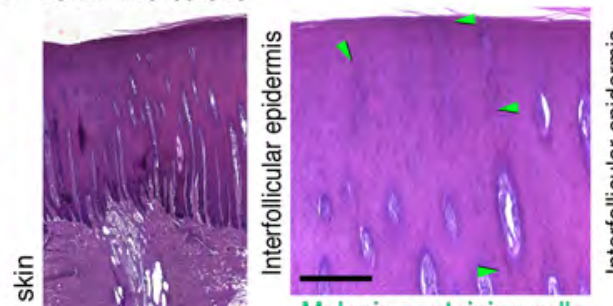

Melanin-containing cells

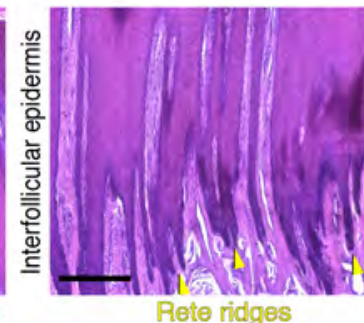

Rete ridges

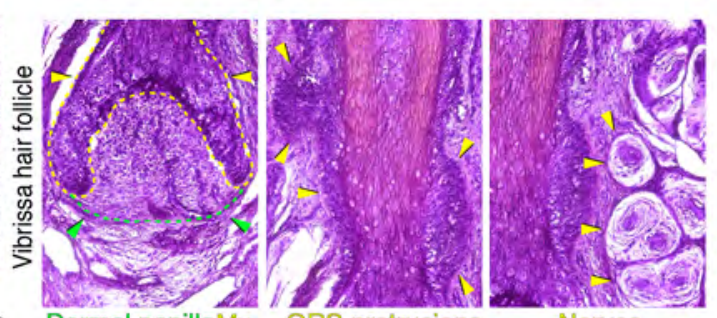

$\mathbf{F}$

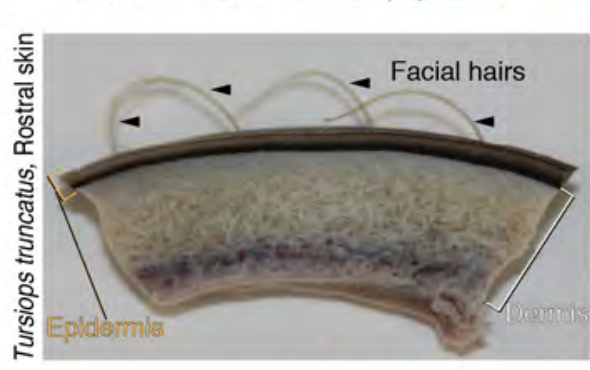

G

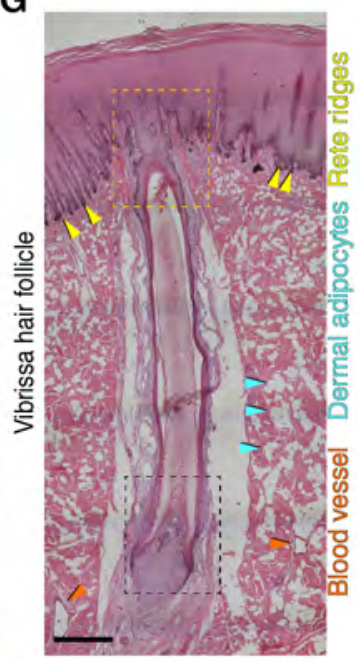

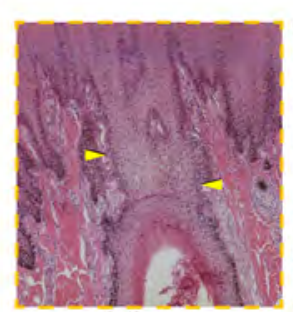

Isthmus

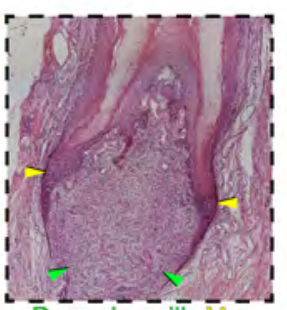

Dermal papilla M $\mathrm{x}$ 


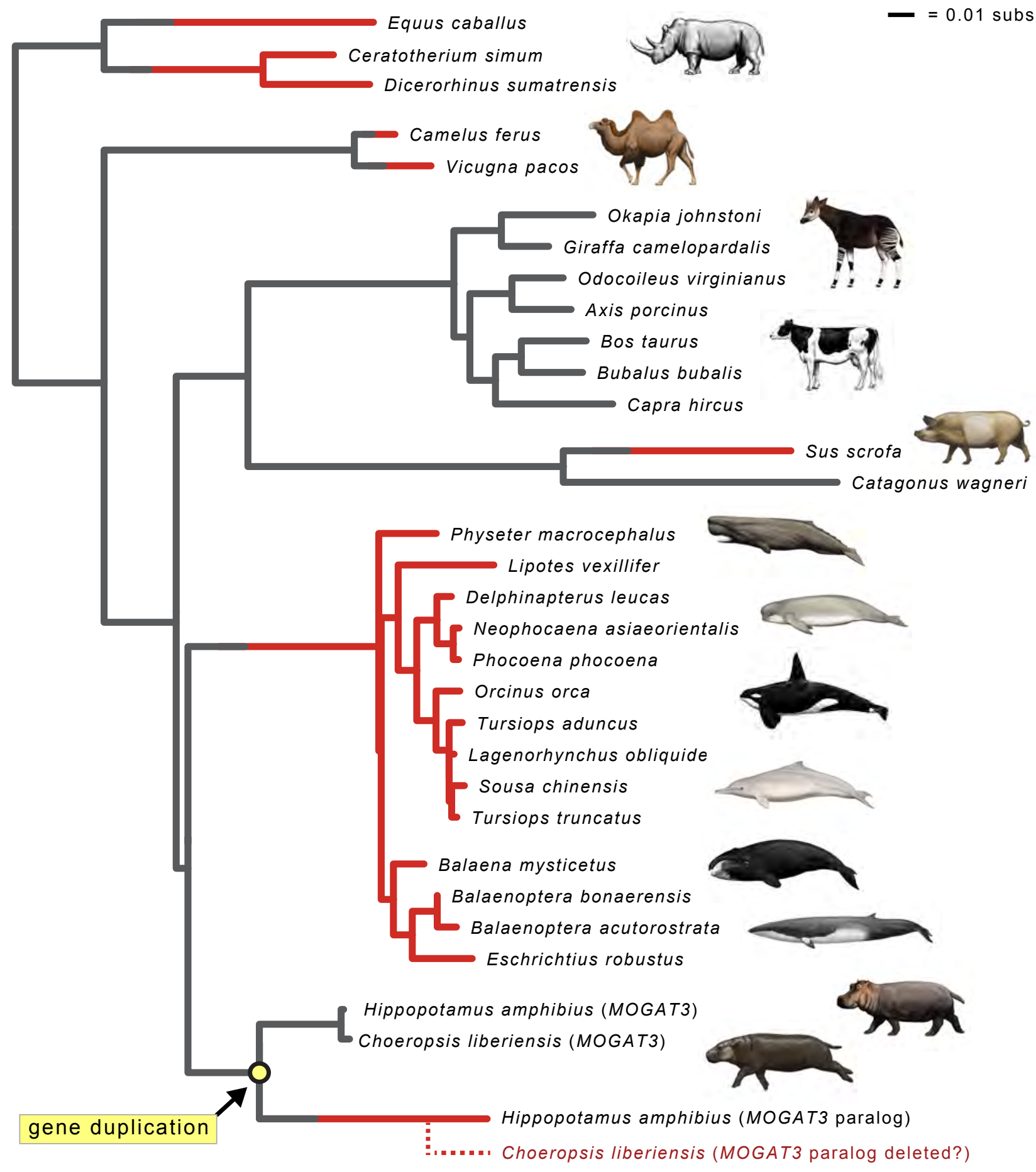

Perissodactyla

Camelidae

Ruminantia

\section{Suoidea}
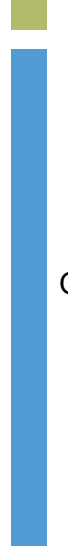

Odontoceti

Mysticeti

Hippopotamidae 


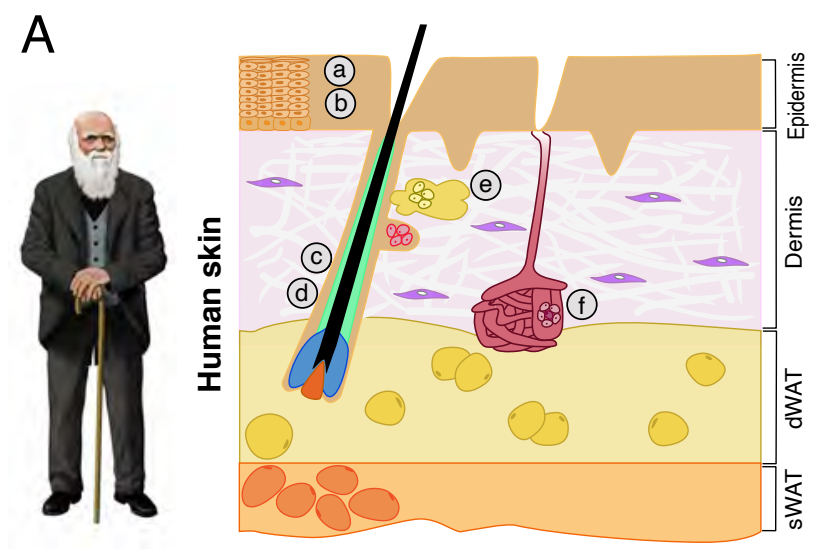

Interfollicular epidermis IFE layers (IFE)

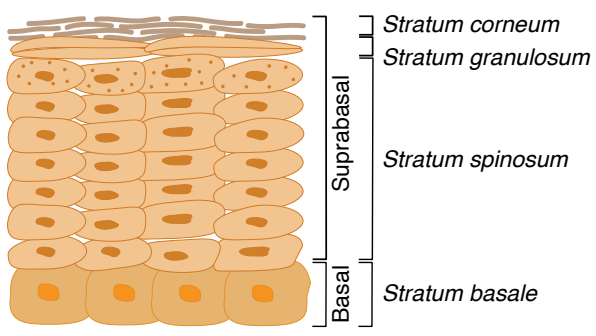

B
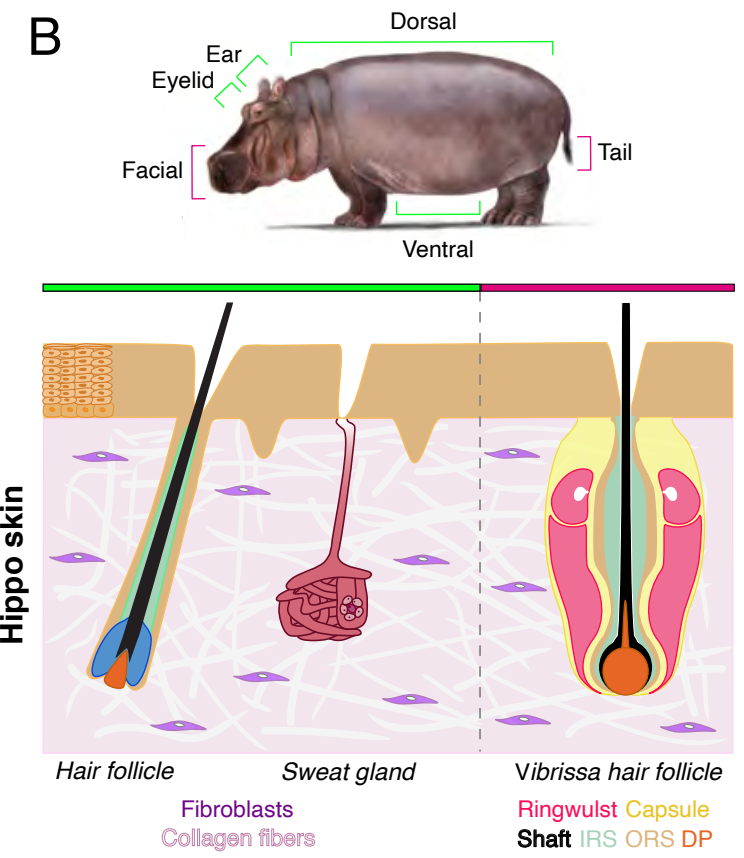

C
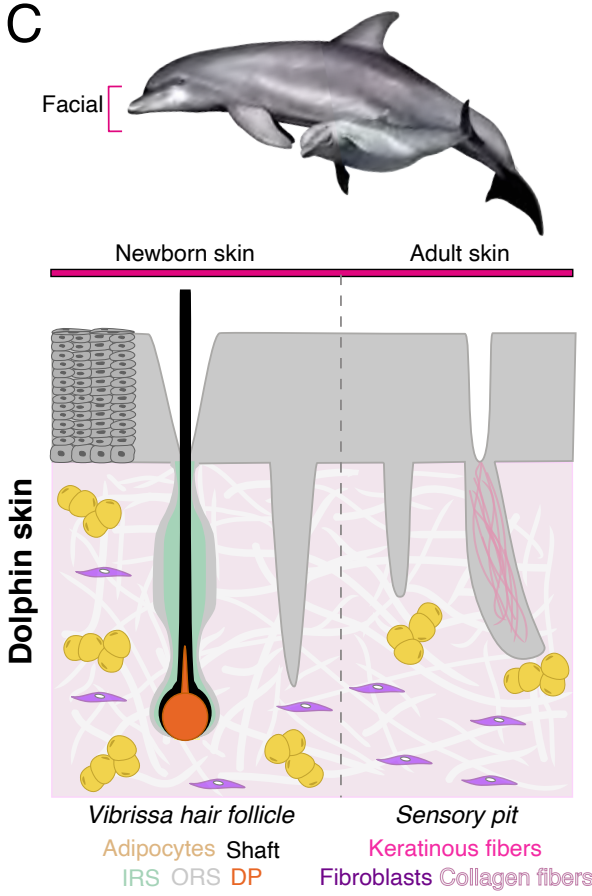

Appendages
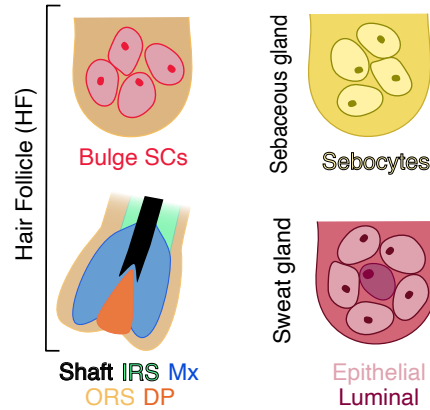

D
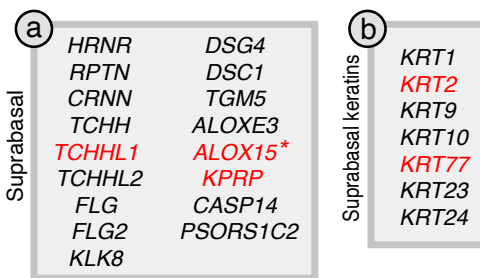

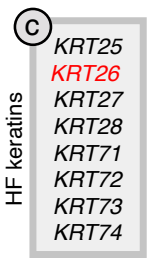

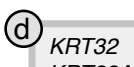

KRT33A

KRT33B

KRT34

KRT35

KRT39

KRT40

స్ KRT82

ч KRT83

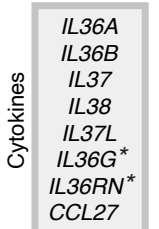
KRT84*

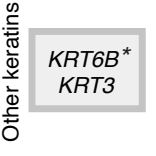

(e) ${ }_{M C 5 R}$

ก FABP9

ELOVL3

AWAT1

DGAT2L6

(f)

$\stackrel{ \pm}{\mathbb{\Phi}} A B C C 11$

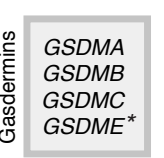


Table 1. Features of the skin in human, cow, pig, hippo, and two cetaceans.

\begin{tabular}{|c|c|c|c|c|c|c|}
\hline $\begin{array}{l}\text { Cellular/anatomical } \\
\text { feature }\end{array}$ & Human & Pig & Cow & Hippo & $\begin{array}{l}\text { Grey whale (facial } \\
\text { skin only) }\end{array}$ & $\begin{array}{l}\text { Common } \\
\text { bottlenose dolphin } \\
\text { (facial skin only) }\end{array}$ \\
\hline Epidermal thickness & 29.6 to $96.5 \mu \mathrm{m}^{\mathrm{a}}$ & 45.8 to $91.7 \mu \mathrm{m}^{\mathrm{b}}$ & 34.9 to $55.6 \mu \mathrm{m}^{\mathrm{c}}$ & $\begin{array}{l}\text { River hippo: } 216 \text { to } \\
1,134 \mu \mathrm{m}^{\mathrm{d}} \text { (adult } \\
\text { trunk); } 42+/-7 \mu \mathrm{m} \\
\text { (neonatal, facial } \\
\text { skin) } \\
\text { Pygmy hippo: } 44 \\
+/-12 \mu \mathrm{m} \\
\text { (neonatal, facial } \\
\text { skin }\end{array}$ & $6,334+/-872 \mu \mathrm{m}$ & $945+/-267 \mu \mathrm{m}$ \\
\hline $\begin{array}{l}\text { Epidermal rete } \\
\text { ridges }\end{array}$ & $\begin{array}{l}\text { Medium-size rete } \\
\text { ridges that differ in } \\
\text { size across body }\end{array}$ & $\begin{array}{l}\text { Medium-size rete } \\
\text { ridges that differ in } \\
\text { size across body }\end{array}$ & $\begin{array}{l}\text { Absence of } \\
\text { definitive rete } \\
\text { ridges }\end{array}$ & $\begin{array}{l}\text { Shallow rete ridges } \\
\text { that differ in size } \\
\text { across body }\end{array}$ & $\begin{array}{l}\text { Prominent, } \\
\text { branched rete ridges }\end{array}$ & $\begin{array}{l}\text { Prominent, } \\
\text { branched rete ridges }\end{array}$ \\
\hline $\begin{array}{l}\text { Cytoplasmic lipid } \\
\text { vacuoles in } \\
\text { epidermal living } \\
\text { layers }\end{array}$ & Absent & N/A & N/A & $\begin{array}{l}\text { Extensive } \\
\text { cytoplasmic lipid } \\
\text { vacuoles in all } \\
\text { epidermal layers }\end{array}$ & $\begin{array}{l}\text { Extensive } \\
\text { cytoplasmic lipid } \\
\text { vacuoles in all } \\
\text { epidermal layers }\end{array}$ & $\begin{array}{l}\text { Extensive } \\
\text { cytoplasmic lipid } \\
\text { vacuoles in all } \\
\text { suprabasal } \\
\text { epidermal layers }\end{array}$ \\
\hline $\begin{array}{l}\text { Lipid distribution in } \\
\text { stratum corneum }\end{array}$ & Inter-cellular & N/A & N/A & $\begin{array}{l}\text { Mostly inter- } \\
\text { cellular }\end{array}$ & $\begin{array}{l}\text { Mostly intra- } \\
\text { cellular }\end{array}$ & $\begin{array}{l}\text { Mostly intra- } \\
\text { cellular }\end{array}$ \\
\hline Stratum basale & Present & Present & Present & Present & Present & Present \\
\hline Stratum spinosum & Present, thin & Present, medium & Present & Present, medium & Present, very thick & Present, very thick \\
\hline Stratum granulosum & Present & Present & Present & Poorly defined & Absent & Absent \\
\hline Stratum corneum & $\begin{array}{l}\text { Present, variable } \\
\text { thickness }\end{array}$ & $\begin{array}{l}\text { Present, variable } \\
\text { thickness }\end{array}$ & Present, thin & Present, medium & Present, very thick & Present, very thick \\
\hline Epidermal barrier & Intact & Intact & Intact & Intact & Disrupted & Disrupted \\
\hline Pelage hair follicles & $\begin{array}{l}\text { Present, variable } \\
\text { hair density across } \\
\text { the body }\end{array}$ & $\begin{array}{l}\text { Present, variable } \\
\text { hair density across } \\
\text { the body }\end{array}$ & $\begin{array}{l}\text { Present, high hair } \\
\text { density }\end{array}$ & $\begin{array}{l}\text { Present, variable } \\
\text { hair density; sparse } \\
\text { over most of the } \\
\text { body }\end{array}$ & Absent & Absent \\
\hline $\begin{array}{l}\text { Vibrissa hair } \\
\text { follicles }\end{array}$ & Absent & Present & Present & Present & $\begin{array}{l}\text { Present, limited to } \\
\text { cranial skin }\end{array}$ & $\begin{array}{l}\text { Present, limited to } \\
\text { cranial skin }\end{array}$ \\
\hline
\end{tabular}




\begin{tabular}{|l|l|l|l|l|l|l|}
\hline $\begin{array}{l}\text { Ability of hair } \\
\text { follicles to cycle }\end{array}$ & Able to cycle & Able to cycle & Able to cycle & Able to cycle & Able to cycle & $\begin{array}{l}\text { Hair follicles cycle } \\
\text { only once in } \\
\text { neonates and } \\
\text { degenerate in adults } \\
\text { to become pits }\end{array}$ \\
\hline $\begin{array}{l}\text { Hair follicle- } \\
\text { associated sebaceous } \\
\text { gland }\end{array}$ & $\begin{array}{l}\text { Present, variable in } \\
\text { size and often } \\
\text { prominent }\end{array}$ & $\begin{array}{l}\text { Present, } \\
\text { rudimentary }\end{array}$ & Present & Absent & Absent & Absent \\
\hline Meibomian glands & Present & Present & Present & Absent & Absent & Absent \\
\hline Sweat glands & $\begin{array}{l}\text { Apocrine and } \\
\text { eccrine glands }\end{array}$ & $\begin{array}{l}\text { Apocrine glands } \\
\text { only }\end{array}$ & $\begin{array}{l}\text { Apocrine glands } \\
\text { only }\end{array}$ & $\begin{array}{l}\text { Eccrine glands } \\
\text { possibly apocrine } \\
\text { glands }\end{array}$ & Absent & $\begin{array}{l}\text { Absent } \\
\text { Dermal adipose } \\
\text { tissue }\end{array}$ \\
\hline
\end{tabular}

${ }^{a}$ Data from Sandby-Møller et al. [124]and Copra et al. [125]

${ }^{b}$ Data from Turner et al. [77].

'Data from Hole et al. [126].

${ }^{\mathrm{d}}$ Glands are specialized and produce "colored" sweat with proposed sunblock and/or antimicrobial properties [41]. 
Table 2. Mean inactivation dates for skin-related genes in cetaceans and hippos based on eight different combinations of codon frequency model (CF1, CF2), fixed versus estimated dN/dS values for the pseudogenic branch category, and one versus two rates for synonymous substitutions. Estimates based on individual analyses are provided in Table S3.

\begin{tabular}{|l|l|l|l|l|l|l|l|}
\hline Gene & Hippopotamidae & Choeropsis & Cetacea & Mysticeti & Balaenoptera & Delphinida & Physeteroidea \\
\hline ABCC11 & & 0 & 40.54 & & & & \\
\hline ALOX15 & 23.54 & & & & 15.74 & 34.13 & 21.44 \\
\hline AWAT1 & 53.92 & & 48.23 & & & & \\
\hline KPRP & 39.01 & & $\begin{array}{l}\text { CDS } \\
\text { deleted }\end{array}$ & & & & \\
\hline KRT2 & 26.41 & & & $33.64^{\mathrm{a}}$ & & & \\
\hline KRT26 & 15.98 & & $48.93^{\mathrm{b}}$ & & & & \\
\hline KRT77 & 45.75 & & $53.92^{\mathrm{c}}$ & & & & \\
\hline $\begin{array}{l}\text { KRTAP } \\
7-1\end{array}$ & 34.18 & 40.94 & & & & \\
\hline MOGAT3 & & & 46.37 & & & & \\
\hline TCHHL1 & 5.42 & & $\begin{array}{l}\text { CDS } \\
\text { deleted }\end{array}$ & & & & \\
\hline
\end{tabular}

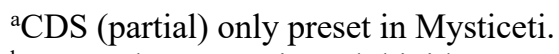

${ }^{\mathrm{b}} \mathrm{CDS}$ only present in Delphinida.

${ }^{\mathrm{c}} \mathrm{CDS}$ only present in Mysticti. 